\title{
Antimicrobial, Conductive, and Mechanical Properties of AgCB/PBS Composite System
}

\author{
Chatchai Veranitisagul, ${ }^{1}$ Worawat Wattanathana ${ }^{\mathbb{D}},{ }^{2}$ Suttipong Wannapaiboon $\left(\mathbb{D},{ }^{3}\right.$ \\ Yuranan Hanlumyuang, ${ }^{2}$ Kankavee Sukthavorn, ${ }^{1}$ Nollapan Nootsuwan, ${ }^{2}$ \\ Siwaruk Chotiwan, ${ }^{4}$ Witchukorn Phuthong, ${ }^{5}$ Suchada Jongrungruangchok, ${ }^{6}$ \\ and Apirat Laobuthee $\mathbb{B}^{2}$ \\ ${ }^{1}$ Department of Materials and Metallurgical Engineering, Faculty of Engineering, \\ Rajamangala University of Technology Thanyaburi, Pathumthani 12110, Thailand \\ ${ }^{2}$ Department of Materials Engineering, Faculty of Engineering, Kasetsart University, Ladyao, Chatuchak, \\ Bangkok 10900, Thailand \\ ${ }^{3}$ Synchrotron Light Research Institute (SLRI), 111 University Avenue, Muang District, Nakhon Ratchasima 30000, Thailand \\ ${ }^{4}$ Department of Chemistry, Faculty of Science, Kasetsart University, Ladyao, Chatuchak, Bangkok 10900, Thailand \\ ${ }^{5}$ Department of Physics, Faculty of Science, Kasetsart University, Ladyao, Chatuchak, Bangkok 10900, Thailand \\ ${ }^{6}$ Department of Pharmaceutical Chemistry, Faculty of Pharmacy, Rangsit University, Pathumthani 12000, Thailand
}

Correspondence should be addressed to Worawat Wattanathana; fengwwwa@ku.ac.th and Apirat Laobuthee; fengapl@ku.ac.th

Received 14 November 2018; Revised 15 March 2019; Accepted 28 March 2019; Published 28 April 2019

Academic Editor: Luqman C. Abdullah

Copyright $\odot 2019$ Chatchai Veranitisagul et al. This is an open access article distributed under the Creative Commons Attribution License, which permits unrestricted use, distribution, and reproduction in any medium, provided the original work is properly cited.

\begin{abstract}
Demand for environmentally friendly plastic materials which are obtained from renewable resources such as biomass-based polyesters is of concern. Herein, the enhanced characteristic performances of poly(butylene succinate) (PBS) by employing the fabrication of PBS-based composites with the nanosilver-coated carbon black (AgCB) using an injection-molding method are reported. The preformed AgCB additives are priorly prepared by the benzoxazine oxidation method. Phase characterization of the obtained composite materials examined by X-ray diffraction (XRD) reveals the crystalline PBS matrix and the presence of metallic silver particles, confirming the successful fabrication of the composite materials. Detailed analyses on thermal, mechanical, electrical, and antimicrobial properties of the composite materials are reported. The AgCB-PBS composite materials provide such potential features by an enhancement of electrical conductivity and the antimicrobial activity by an inhibition against $E$. coli and $C$. albicans. These AgCB-PBS composite materials show the possibility to be an option for antielectrostatic and antimicrobial applications such as for the production of smart, environmentally friendly keyboards.
\end{abstract}

\section{Introduction}

Nowadays, pollution caused by tremendously large amount of usage and disposal of petroleum-based plastic materials is of concern all over the world [1-3]. Moreover, demand for reusing and also value adding of industrial and agricultural by-products are crucial, especially in developing countries $[4,5]$. Therefore, environmentally friendly materials obtained from renewable resources have attracted significant attention. Biomass-based polyesters such as poly(lactic acid)
(PLA) [6, 7], poly(3-hydroxybutyrate) (PHB) [8, 9], and poly(butylene succinate) (PBS) [10-12] are among such materials. In particular, PBS has received enormous attention as it is gradually biodegraded in the landfill or sea in the presence of bacteria or fungi [13]. Moreover, PBS can be processed as easily as commercially available, petroleumbased plastics by using a variety of techniques such as blown films, fibers spinning, injection molding, thermoforming, or blow molding [14]. However, its potential for extensive applications has been limited by it slow melt viscosity as well 
as a high cost of production of PBS-based products $[15,16]$. To reduce the production cost and to improve the characteristic features of PBS, several strategies have been employed including blended or composite materials consisting of the PBS polymer matrix and a variety of biodegradable additives such as cellulose [17, 18], various plant fibers [19-22], starch [23-25], and soy protein [26, 27].

As mentioned that additives could improve the properties of polymers, several organic and inorganic fillers have been used as the additives for the preparation of polymerbased composites. Carbon black (CB) is one of the most popular additives that are known for improving the mechanical properties of polymer matrices, such as tensile strength, tear strength, hardness, and abrasion resistivity. Apart from these properties, its inexpensive cost makes $\mathrm{CB}$ suitable for large-scale production. Furthermore, CB has been shown to increase the electrical [28-30] and thermal conductivities of the composite materials [31].

Silver nanoparticles are renowned for their incredible physical, chemical, and biological properties [32]. Due to its high thermal stability and ability to inhibit the growth of various microorganisms, silver nanoparticles exhibit potentially useful addition as another additive for PBS $[33,34]$. Our research group has developed a new method for preparing silver nanoparticles and then coating the nanoparticles onto the different substrates using benzoxazine as a reducing agent [35]. Different types of substrates, i.e., $\mathrm{SiO}_{2}, \mathrm{TiO}_{2}$, glass slides, polycarbonate (PC) sheets, polyvinyl alcohol (PVA), and chitosan (CS) powder as well as carbon black (CB) powder, were successfully coated with silver nanoparticles using this method [35]. The procedure occurred easily at room temperature, and any solvent or medium can be used. Moreover, this method did not disturb the structure of substrates, so the characteristic properties of the materials remain. Therefore, the properties of silver nanoparticles can be added without altering the original features of the substrates.

In this paper, enhanced PBS characteristics for antimicrobial, conductive, and mechanical properties have been examined by preparing PBS-based composites between PBS as the polymer matrix and carbon black (CB) or nanosilvercoated carbon black (AgCB) as its additive. The AgCB additive was priorly prepared by using a benzoxazine oxidation reaction for using as a filler. Two types of PBS-based composites were fabricated, namely, carbon black blended in PBS (CB-PBS) and nanosilver-coated carbon black blended in PBS (AgCB-PBS), varying the percentage of the additives for $3,5,10$, and $15 \%$. Note that the notations of $x \mathrm{CB}-\mathrm{PBS}$ and $x \mathrm{AgCB}-\mathrm{PBS}$ ( $x$ is the percentages of the additives) are used throughout this article. The phase formation of the novel composites was characterized by X-ray diffraction (XRD). Details on the characterization of their thermal properties, mechanical properties, electrical properties, and antimicrobial properties were thoroughly examined and discussed. As a highlight of this work, the AgCB-PBS composites provide improved antimicrobial and electrical properties, while maintaining the mechanical stability in comparison with the pure PBS. The obtained AgCB-PBS composite materials with good antimicrobial and antielectrostatic properties could be a good candidate for further use in the production of keyboards. Furthermore, these obtained PBS-based composites are also biodegradable, of which the disposal problems after the end of use can be manageable.

\section{Experimental}

2.1. Chemicals and Materials. 3,4-Dihydro-3,6-dimethyl$1,3,2 \mathrm{H}$-benzoxazine, the reducing agent used for the synthesis of silver nanoparticles coated on $\mathrm{CB}$, was synthesized by the method reported previously [35]. Poly(butylene succinate) (PBS) used in this work was an injection grade FZ71PD from Mitsubishi Co. Ltd. All chemicals and materials were used as received without prior characterization.

\subsection{Preparation of Nanosilver-Coated Carbon Black (AgCB).} For the preparation of nanosilver-coated carbon black (AgCB), $10 \mathrm{~g}$ of carbon black was weighed and then put in a beaker containing $10 \mathrm{~cm}^{3} \mathrm{CH}_{2} \mathrm{Cl}_{2}$. The mixture was then stirred for 3 minutes. After that, the solution of the synthesized reducing agent in $\mathrm{CH}_{2} \mathrm{Cl}_{2}\left(1 \mathrm{~g} / 10 \mathrm{~cm}^{3}\right)$ and $1 \mathrm{~g}$ of $\mathrm{AgNO}_{3}$ were added to the reaction mixture. Then, the mixture was continuously stirred for a further $8 \mathrm{~h}$ to complete the coating of silver onto the carbon black. The obtained $\mathrm{AgCB}$ product was filtered out and then washed with $\mathrm{CH}_{2} \mathrm{Cl}_{2}$ for 2 times and additionally with acetone for 1 time to remove organic impurities. The product was dried at $75^{\circ} \mathrm{C}$ for $3 \mathrm{~h}$. After that, the obtained powder was sieved to reduce the particle sizes to be less than $150 \mu \mathrm{m}$. The success of nanosilver coating on the carbon black substrate was confirmed by field emission scanning electron microscopy (FESEM, obtained by a JSM-7600F, JEOL) and transmission electron microscopy (TEM, collected by a TEM-Hitachi, HT7700).

\subsection{Preparation of Poly(butylene succinate)- (PBS-) Based} Composite Materials. Composite materials of PBS and CB, herein called as CB-PBS, were prepared from their compound pellets. Prior to the reaction, PBS (grade 2003D) was dried in an oven at $40^{\circ} \mathrm{C}$ for $24 \mathrm{~h}$. Next, a small amount of vegetable oil was added so that the additives $\mathrm{CB}$ or $\mathrm{AgCB}$ can stick in the PBS matrix quickly. The amount of additives $(\mathrm{CB}$ or $\mathrm{AgCB}$ ) was added by varying the percentages of $3,5,10$, and $15 \%$ with respect to the PBS amount.

Melt flow index (MFI) of PBS, CB-PBS, and AgCB-PBS composites was investigated to get the information about processing conditions. The initial temperature for the test was set to be $170^{\circ} \mathrm{C}$, and the pressing force was set to be $2.16 \mathrm{~kg}$. Dumbbell-shaped samples of PBS, CB-PBS, and AgCB-PBS composites were fabricated by an injection molding method using a Battenfeld machine (BA 250).

2.4. Characterization and Properties Test of PBS-Based Composite Materials. The phase formation of the composite materials was investigated by X-ray diffraction (XRD) using an X-PertPRO MPD diffractometer $\left(\mathrm{Cu} K_{\text {alpha }}\right.$ 
radiation, Nickel filter, scan step $=0.02^{\circ}$ ). Moreover, the crystallinity at the surface of composite materials was also characterized by using grazing incidence $\mathrm{X}$-ray diffraction (GIXRD) at beamline BL1.1W (Multiple X-ray Techniques, MXT) at Synchrotron Light Research Institute (SLRI), Thailand (using synchrotron monochromatic $\mathrm{X}$-ray radiation of energy $12 \mathrm{keV}$ or wavelength of $1.0322 \AA$, twodimensional image plate MAR345 detector, incidence angle of 0.5 degrees, and sample-to-detector distance of approximately $170 \mathrm{~cm}$ ). The 2-dimensional diffraction patterns were further integrated in order to obtain the 1-dimensional XRD patterns using Fit2d software. The XRD pattern of the NIST standard lanthanum hexaboride $\left(\mathrm{LaB}_{6}\right)$ was collected in order to calibrate the sample-to-detector distance used in this experimental setup.

Thermal properties of the prepared composite materials were examined by thermogravimetric analysis (TGA) and differential scanning calorimetry (DSC) using a TGA/DSC 1 METTLER TOLEDO STARe SYSTEM with a heating rate of $10^{\circ} \mathrm{C} / \mathrm{min}$. Mechanical properties of the prepared composite polymers were further studied according to the standard ASTM D 638-03. Tensile strength was studied by a universal testing machine (UTM). According to the ASTM D 683-03 standard, the tensile force was created from $1000 \mathrm{~kg}$ weight with the moving speed of $5 \mathrm{~mm} / \mathrm{min}$. The force was continuously applied until the sample was broken so that the tensile strength can be measured in either $\mathrm{kg} / \mathrm{cm}^{2}$ or N/mm . Furthermore, \% elongation at break can be calculated using the formula given below:

$$
\% \text { elongation at break }=\left[\frac{(\text { final length }- \text { initial length })}{\text { initial length }}\right] \times 100 \text {. }
$$

For the electrical conductivity test, the prepared composite materials were cut into square-shaped samples and then glued using silver paint. The resistance can be measured by applying the voltage of 1000 Volts for $30 \mathrm{mins}$. The resistivity of the materials can be calculated from the equation: $\rho=R \times A / L$, where $\rho=$ resistivity, $R=$ resistance, $A=$ crosssectional area, and $L=$ length.

Antibacterial and antifungal tests of prepared samples were examined using the agar disk diffusion method [36]. Two types of media were used in this study: (1) sterile Mueller-Hinton agar (MHA) was used for bacteria cultivation and (2) sterile Sabouraud's dextrose agar (SDA) was used for yeast cultivation. The inoculum suspension was prepared by incubating a pure culture of the test microorganisms at $37^{\circ} \mathrm{C}$ for $18 \mathrm{~h}$. Then, the incubated microbes were transferred to the liquid media to adjust the turbidity to be $0.5 \mathrm{McF}$ arland turbidity standard. A sterile cotton swab was dipped into the prepared inoculum and was then swabbed over the entire surface of the agar. The microorganisms used as the samplings in this study were Micrococcus luteus (M. luteus) ATCC 9341, Staphylococcus aureus (S. aureus) ATCC 25923, Bacillus subtilis (B. subtilis) ATCC 6633, Escherichia coli (E. coli) ATCC 25922, Candida albicans (C. albicans) ATCC 10231, and Pseudomonas aeruginosa (P. aeruginosa) ATCC 27853. The fabricated PBS-based composite materials were cut in square-shaped samples and then placed in the Petri dish. The Petri dish was incubated at $37^{\circ} \mathrm{C}$ for $18-24 \mathrm{~h}$ for bacteria but $72 \mathrm{~h}$ at $30^{\circ} \mathrm{C}$ for fungi. The clear zone was observed, and the size of the inhibition area was recorded.

\section{Results and Discussion}

The melt flow study of the pristine PBS, CB-PBS, and AgCBPBS composite materials was carried out at $170^{\circ} \mathrm{C}$ using the pressing weight of $2.16 \mathrm{~kg}$, following the ASTM D1238 standard method. The flow rate of pristine PBS was $32.142 \mathrm{~g} /$ $10 \mathrm{~min}$. When the CB filler was added for $10,20,30$, and $40 \mathrm{phr}$ (per hundred resin) of CB with respect to the content of PBS matrix, the flow rates were decreased to 19.158, 5.766, 2.412 , and $0.768 \mathrm{~g} / 10 \mathrm{~min}$, respectively (Figure 1 ). This result suggested that the content of $\mathrm{CB}$ additive is limited to be not higher than $20 \mathrm{phr}$. Therefore, the variation of CB contents of $3,5,10$, and $15 \mathrm{phr}$ was used in this study, hereafter coined as 3CB-PBS, 5CB-PBS, 10CB-PBS, and 15CB-PBS, respectively. The photographic images of the fabricated products (illustrated in Figure 2) indicate the successful preparation of the homogeneous, translucent dumbbellshaped plastics.

To get insight into the details of phase formation and crystallinity of the as-fabricated products, XRD patterns of the pristine PBS, as well as the $x$ CB-PBS composite materials, are collected. The XRD patterns (Figure 3 ) reveal the formation of crystalline PBS phase in all the cases. In detail, the pristine PBS shows the characteristic diffraction peaks at $2 \theta$ of $19.5^{\circ}, 21.9^{\circ}$, and $22.6^{\circ}$ which are indexed corresponding to the planes (020), (021), and (110) of PBS, respectively [37]. No additional XRD peaks are observed in the $x$ CB-PBS composite materials, indicating that the $\mathrm{CB}$ additive used herein is amorphous. Note that, the diffraction peaks of the PBS matrix still remain in the composites. This observation shows that the addition of the $\mathrm{CB}$ filler does not disrupt the crystalline structure of the PBS matrix. To identify the existence of CB filler, SEM images of the pristine PBS and the as-fabricated $x \mathrm{CB}$-PBS composites are compared (Figure 4). The surfaces of the $x \mathrm{CB}$-PBS composites are composed of many fine particles embedded within the rather smooth PBS matrix (as observed in the case of pristine PBS). This observation indicates the good distribution of $\mathrm{CB}$ particles within the whole PBS matrix. Note that, the elemental mapping analyzed by energy dispersive X-ray spectroscopy (EDS) cannot be used to identify the distribution of $\mathrm{CB}$ within the PBS matrix due to the similar elemental contribution, i.e., $C$ in both species.

To further examine the enhanced characteristic features of the composites by means of the addition of $\mathrm{CB}$ filler, thermal properties of the pristine PBS and CB-PBS composites were studied (Figure 5). DSC curves were recorded from -50 to $200^{\circ} \mathrm{C}$ under a nitrogen atmosphere to study the temperature related to phase transition of polymers, while the TGA thermograms were recorded from 0 to $1000^{\circ} \mathrm{C}$ under an oxygen atmosphere to examine the thermal stability and the amount of residues after thermal treatment. According to DSC thermogram (Figure 5(a)), the pristine PBS shows the glass transition temperature $\left(T_{\mathrm{g}}\right)$ at $-61^{\circ} \mathrm{C}$ and 


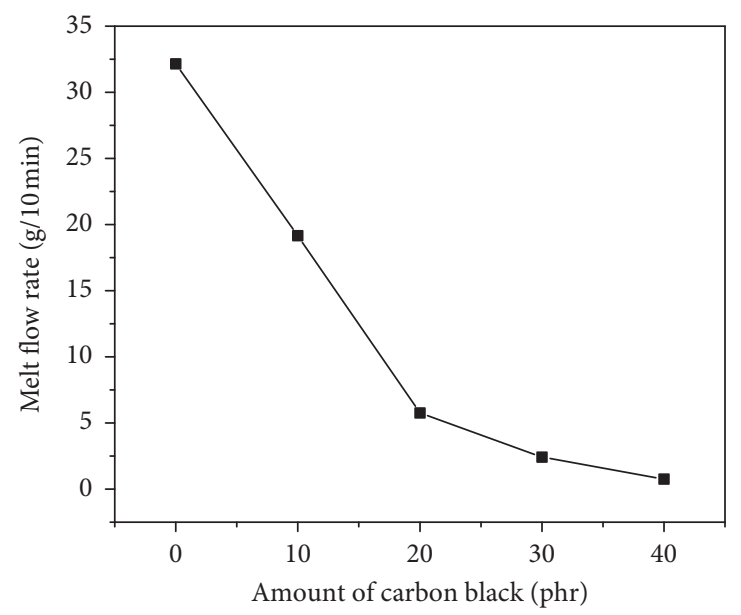

FIgure 1: Melting flow rate of pristine PBS and $x$ CB-PBS composites ( $x=$ percentages of CB additive with respect to the amount of PBS matrix). Note that the solid line is only used as a guide to the eye.

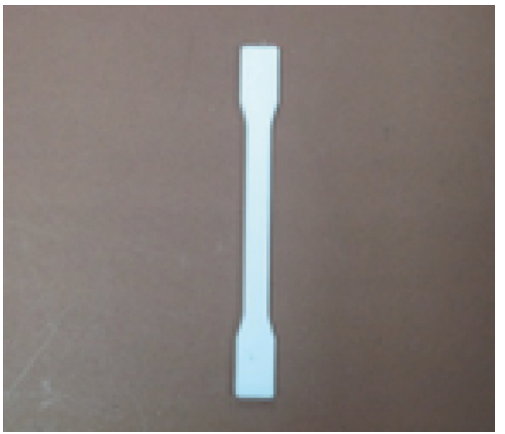

(a)

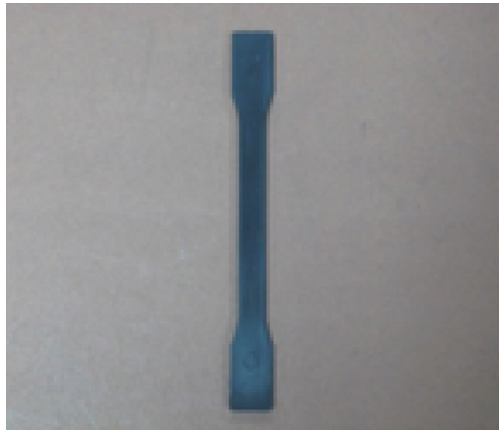

(b)

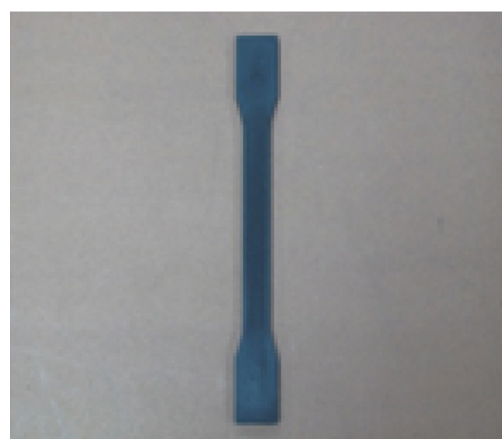

(c)

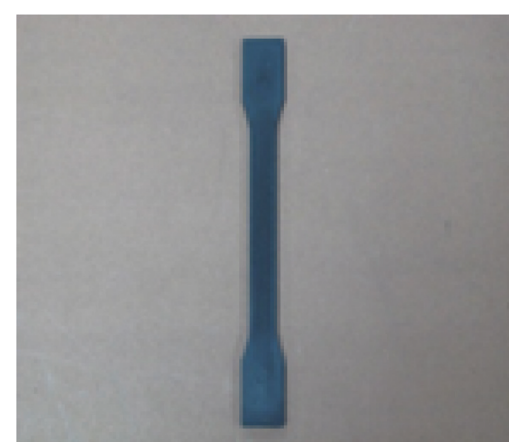

(d)

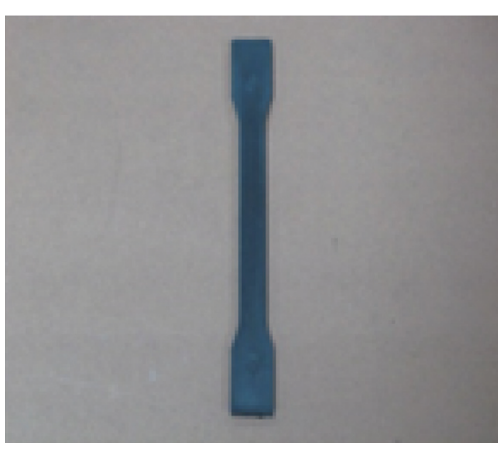

(e)

Figure 2: Photographic images showing physical appearance of (a) pristine PBS, (b) 3CB-PBS, (c) 5CB-PBS, (d) 10CB-PBS, and (e) 15CBPBS composite materials after proceeded by an injection molding method.

the endothermic melting peak $\left(T_{\mathrm{m}}\right)$ at $117^{\circ} \mathrm{C}$. Interestingly, the addition of CB filler in the CB-PBS composite materials reduces the $T_{\mathrm{g}}$ to be -63 to $-64^{\circ} \mathrm{C}$ and also reduce the $T_{\mathrm{m}}$ to be at $115^{\circ} \mathrm{C}$. TGA thermograms in Figure 5(b) show that the decomposition of pristine PBS starts to occur at the temperature around $300^{\circ} \mathrm{C}$ corresponding to the breaking down of the PBS molecules. The presence of CB filler in $x \mathrm{CB}-\mathrm{PBS}$ composites, especially in case of 15CB-PBS (the magenta plot (e) in Figure 5(b)) with the highest CB content herein, shifts the decomposition temperature to be higher than the one of the pristine PBS. The drastic change of weight loss is observed at about $400^{\circ} \mathrm{C}$, and the weight of the residue is completely stable at the temperature of $550^{\circ} \mathrm{C}$. The further increasing of temperature up to $1000^{\circ} \mathrm{C}$ shows no additional change of the residue weight, ensuring the complete thermal decomposition of the PBS-base materials. There is no significant trend of the residual weights of pristine PBS, 3CBPBS, 5CB-PBS, 10CB-PBS, and 15CB-PBS, which are 0.28, $0.12,0.53,0.21$ and 0.44 , respectively.

Mechanical properties of pristine PBS and $x \mathrm{CB}-\mathrm{PBS}$, namely, tensile strength, elongation at break, impact strength, and bending strength were examined. Tensile 


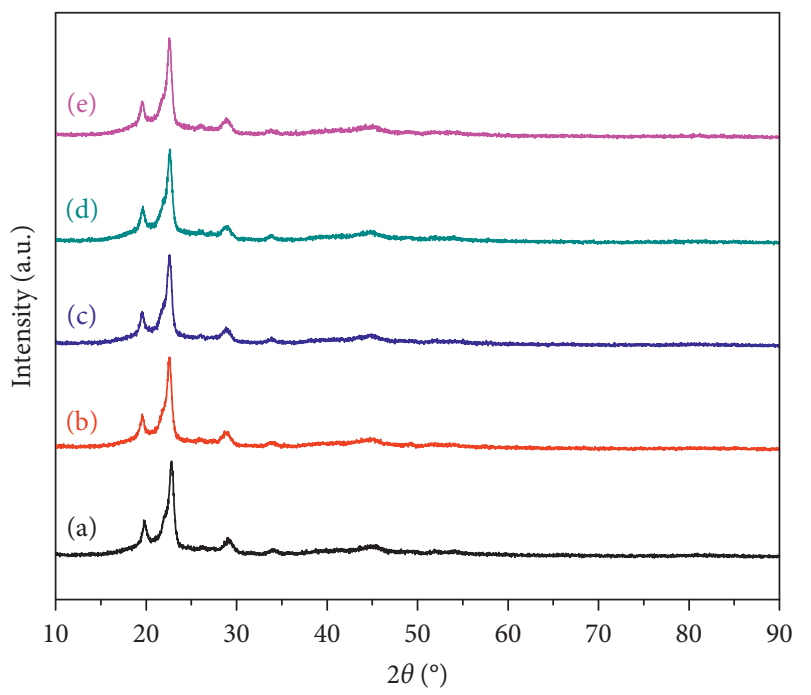

FIGURE 3: XRD patterns using X-ray of $\mathrm{Cu} K_{\text {alpha }}$ radiation of the as-synthesized (a) pristine PBS, (b) 3CB-PBS, (c) 5CB-PBS, (d) 10CB-PBS, and (e) 15CB-PBS materials indicating the crystalline phase of PBS. The addition of CB shown herein as amorphous phase does not disrupt the structure of PBS matrix.

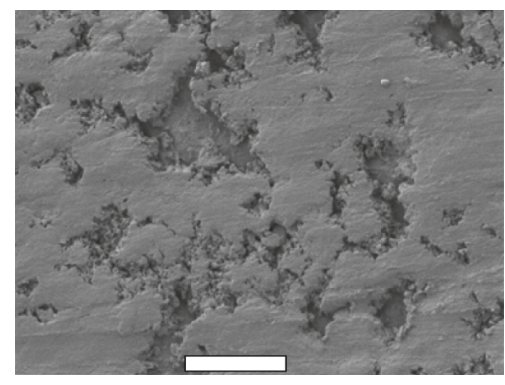

(a)

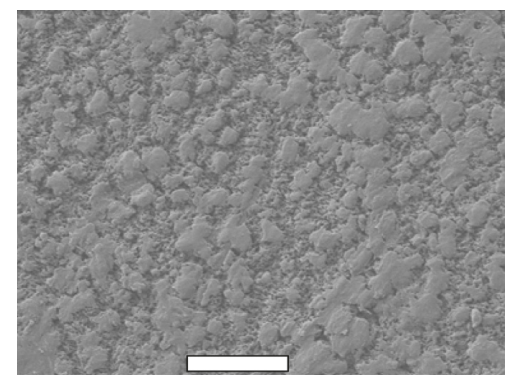

(b)

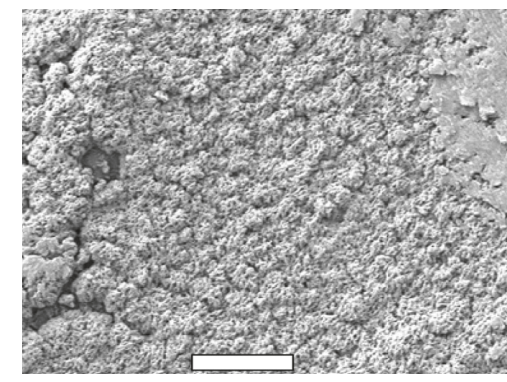

(c)

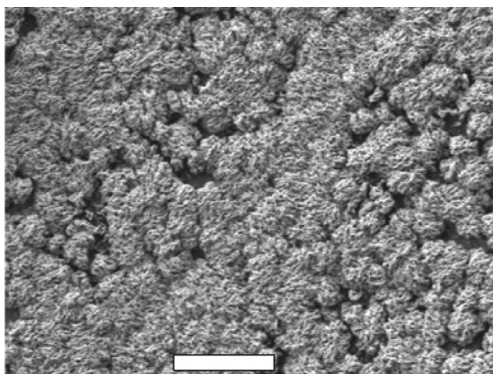

(d)

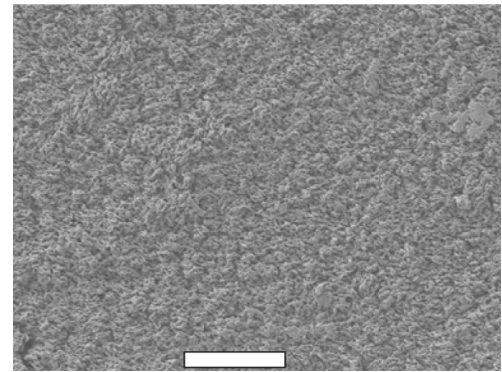

(e)

Figure 4: SEM images of (a) pristine PBS, (b) 3CB-PBS, (c) 5CB-PBS, (d) 10CB-PBS, and (e) 15CB-PBS. Scale bar shown here is equal to $10 \mu \mathrm{m}$.

strength was studied by following the ASTM D638 standard and using a crosshead speed of $50 \mathrm{~mm} / \mathrm{min}$. In detail, tensile strength of the pristine PBS is $41.47 \pm 0.24 \mathrm{MPa}$, while ones of the 3CB-PBS, 5CB-PBS, 10CB-PBS, and 15CB-PBS are $36.83 \pm 0.65,33.29 \pm 0.53,35.98 \pm 0.13$, and $34.77 \pm 1.17 \mathrm{MPa}$, respectively (Figure 6(a)). In addition, elongation at break of the pristine PBS is $16.30 \pm 0.74 \%$ while ones of the $3 \mathrm{CB}-\mathrm{PBS}$, 5CB-PBS, 10CB-PBS, and 15CB-PBS are $13.04 \pm 0.15 \%$, $8.28 \pm 0.58 \%, 12.97 \pm 0.44 \%$, and $8.12 \pm 0.77 \%$, respectively (Figure 6(b)). Impact strength of the pristine PBS is $2.95 \pm 0.46 \mathrm{~kJ} / \mathrm{m}^{2}$, and ones of the 3CB-PBS, 5CB-PBS,
$10 \mathrm{CB}-\mathrm{PBS}$, and $15 \mathrm{CB}-\mathrm{PBS}$ are $2.36 \pm 0.60,2.08 \pm 0.57$, $2.35 \pm 0.20$, and $2.16 \pm 0.30 \mathrm{~kJ} / \mathrm{m}^{2}$ (Figure $6(\mathrm{c})$ ). In general, the addition of $\mathrm{CB}$ filler into PBS to form the $x \mathrm{CB}-\mathrm{PBS}$ composites slightly decreases tensile strength, elongation at break, and impact strength in comparison with the pristine PBS as also observed in the literature [38]. However, there is no trend of the change with respect to the content of $\mathrm{CB}$ additives. Unlike the previously mentioned mechanical properties, the higher amount of $\mathrm{CB}$ additives leads to the lowering of bending strength from the pristine PBS (of 101.84 $\mathrm{MPa}$ ) to the composites 3CB-PBS (of 101.69 MPa), 


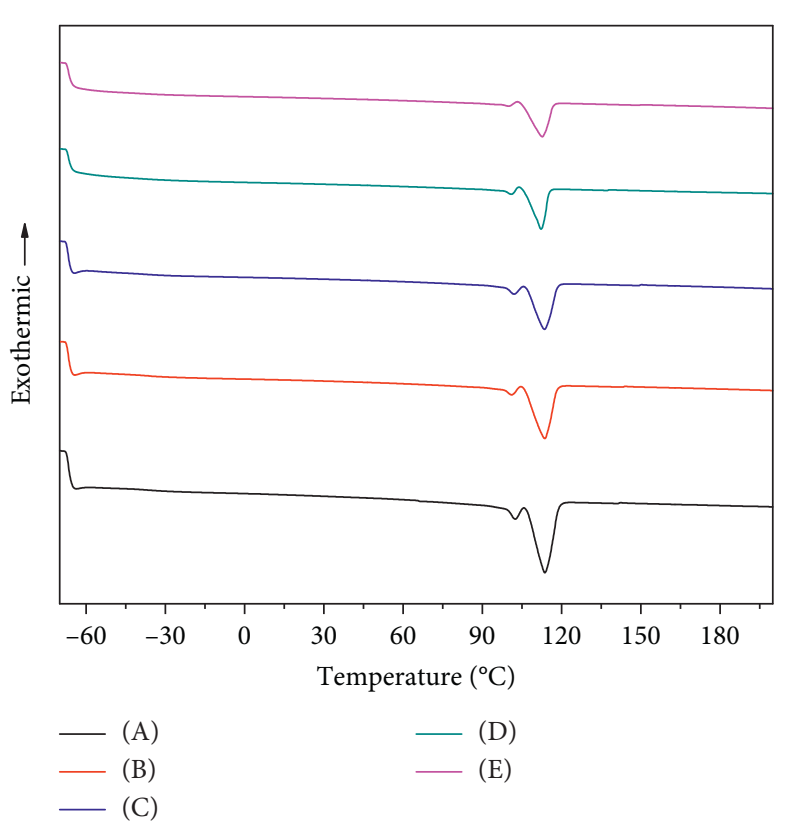

(a)

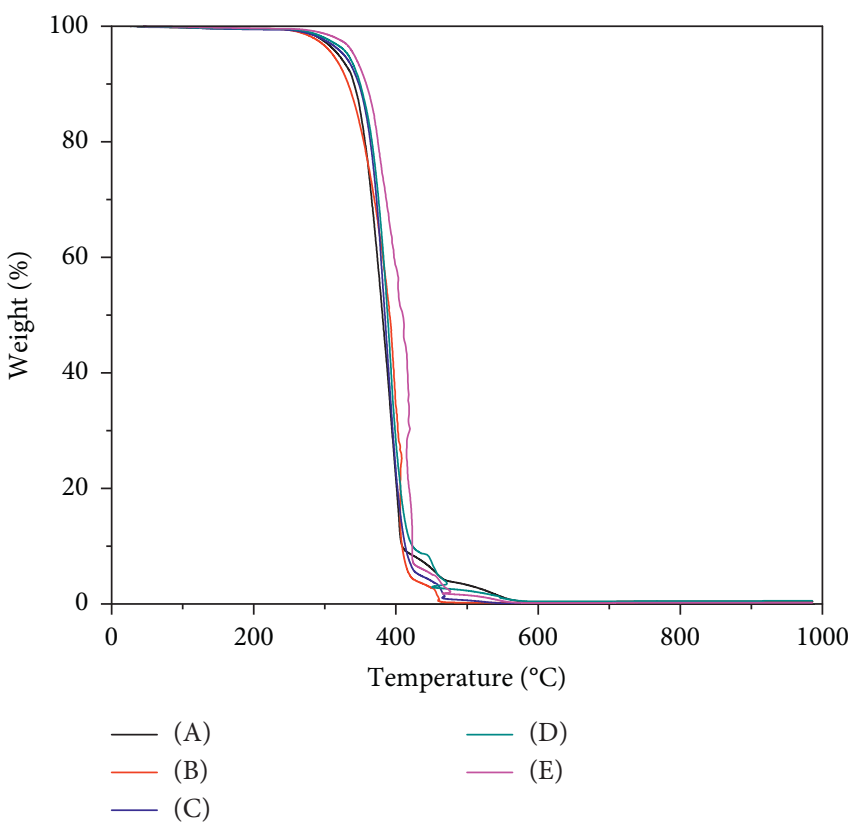

(b)

FIgure 5: (a) DSC and (b) TGA thermograms of the pristine PBS and xCB-PBS composite materials. Note that the labels shown in the plots represent the materials as follows: (A) pristine PBS, (B) 3CB-PBS, (C) 5CB-PBS, (D) 10CB-PBS, and (E) 15CB-PBS.

5CB-PBS (of 92.39 MPa), 10CB-PBS (of $82.95 \mathrm{MPa}$ ), and 15CB-PBS (of $71.77 \mathrm{MPa}$ ). Even though the composites materials reveal a reduction of mechanical strengths from the pristine PBS, they are still within the acceptable range to be used in similar fashions as the PBS-based polymers.

For the further step, we additionally integrated the properties of silver nanoparticles into the PBS-based composites in order to enhance their characteristic features. Firstly, the additive so-called nanosilver-coated carbon black (AgCB) was prepared by the benzoxazine oxidation method [35]. SEM and TEM images of the synthesized products shown in Figure 7 indicate the successful incorporation of silver nanoparticles onto the carbon black substrate. As shown in the TEM image, the approximately $2 \mathrm{~nm}$-sized $\mathrm{Ag}$ particles are embedded and well distributed within the spherical $\mathrm{CB}$ matrix. These obtained $\mathrm{AgCB}$ particles were further integrated into the PBS matrix with a variation of percentages of $3,5,10$, and $15 \%$. The phase formation of the as-fabricated $x$ AgCB-PBS composite materials $(x=$ percentages of $\mathrm{AgCB}$ with respect to the PBS content) was characterized by XRD. The XRD patterns of the AgCB-PBS composite materials (Figure 8) reveal the diffraction peaks of the PBS matrix as having been observed in the cases of CBPBS composites. Moreover, there are some additional XRD peaks at $2 \theta$ of $38.41^{\circ}, 43.34^{\circ}, 66.37^{\circ}, 77.15^{\circ}$, and $81.32^{\circ}$, which can be indexed as (111), (200), (311), and (222) of the metallic silver (JCPDS 04-0783), respectively. This evidence clearly shows the successful incorporation of $\mathrm{AgCB}$ additive into the PBS matrix and the remaining phase formation of all components within the composites. Moreover, SEM images of the as-fabricated $x \mathrm{AgCB}-\mathrm{PBS}$ composites (Figure 9) also show that the composites consist of many fine $\mathrm{AgCB}$ particles embedded within the PBS matrix. The EDS elemental mappings of C (Figure 9(f)), O (Figure 9(g)), and importantly $\mathrm{Ag}$ (Figure 9(h)) clearly identify the good distribution of AgCB additives within the PBS matrix.

AgCB-PBS composite materials were subjected to studying thermal properties (Figure 10). Here again, the DSC curves were recorded from -50 to $200^{\circ} \mathrm{C}$ under a nitrogen atmosphere to study the temperature related to phase transition of polymers. Interestingly, the incorporation of $\mathrm{AgCB}$ into the PBS matrix reduces the glass transition temperature to be at -63 to $-64^{\circ} \mathrm{C}$ and the endothermic melting peak to be at $114^{\circ} \mathrm{C}$, which is even lower than the case of CB-PBS composites (Figure 10(a)). TGA thermograms of AgCB-PBS composite materials decomposed under an oxygen atmosphere (Figure 10(b)) show the most considered weight loss at the temperature from 300 to $320^{\circ} \mathrm{C}$. This is assigned to be the decomposition of PBS matrix phase. In the similar fashion with the DSC results, the decomposition temperature of the AgCB-PBS composites is slightly lower than the one of CB-PBS composites and also the pristine PBS since the silver nanoparticles coated on the CB surface can conduct heat very well. Therefore, it speeds up the thermal decomposition to occur at a lower temperature. Noted that, the residuals after thermal treatment are $1.90,1.87,1.07$, and $0.99 \mathrm{wt} . \%$, respectively, which are proved to be metallic silver $[39,40]$.

Moreover, the study on mechanical properties of AgCBPBS was also performed in a similar way as the CB-PBS materials (Figure 11). Here again, the addition of $\mathrm{AgCB}$ filler into PBS slightly reduces tensile strength, elongation at break, impact strength, and bending strength of the composites in comparison with the pristine PBS in the similar fashion as the cases of $\mathrm{CB}$ additive. This observation clearly shows that the mechanical properties of the 


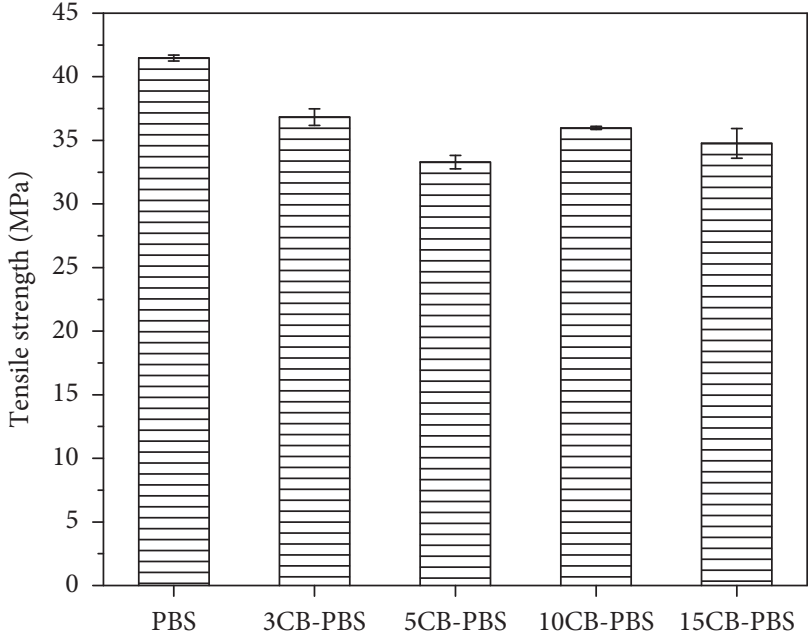

(a)

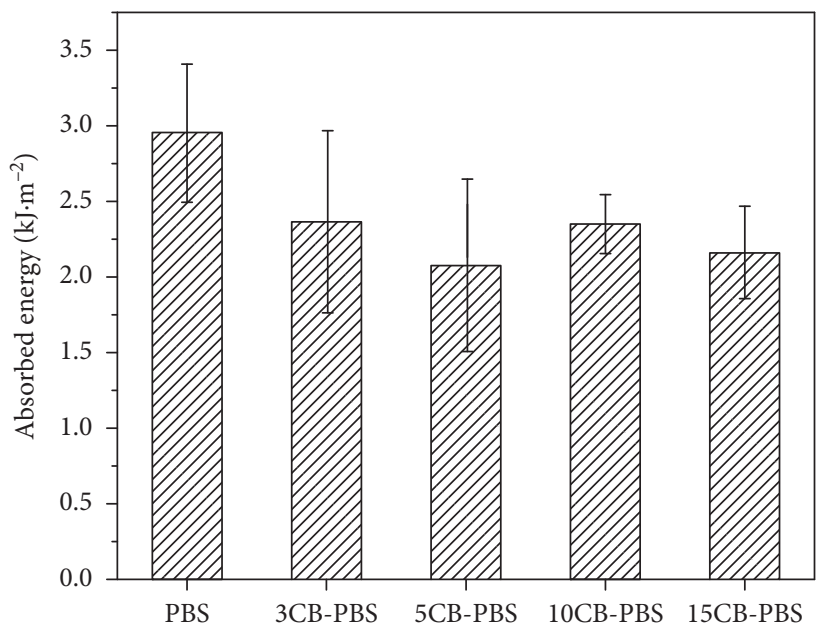

(c)

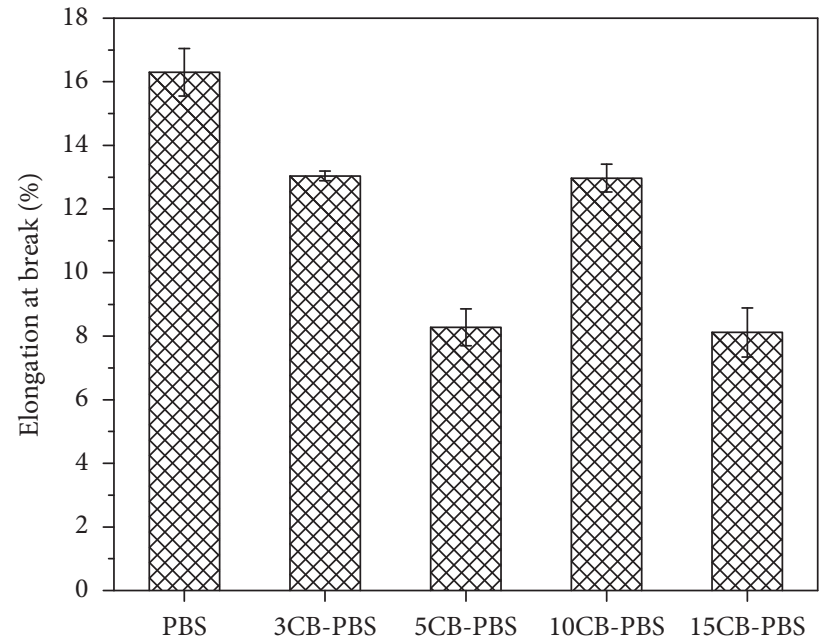

(b)

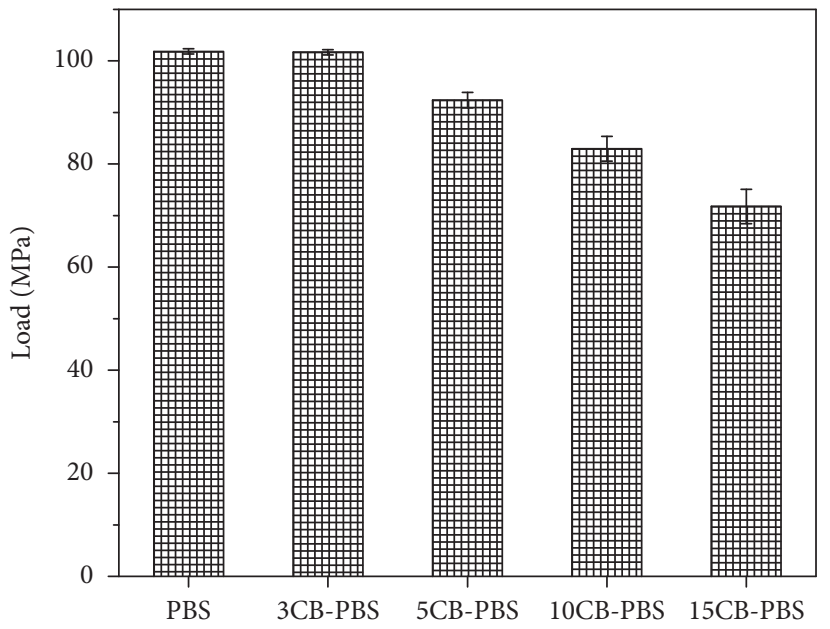

(d)

FIGURE 6: (a) Tensile strength, (b) elongation at break, (c) impact strength, and (d) bending strength of the pristine PBS as well as the $\mathrm{xCB}$ PBS composite materials.

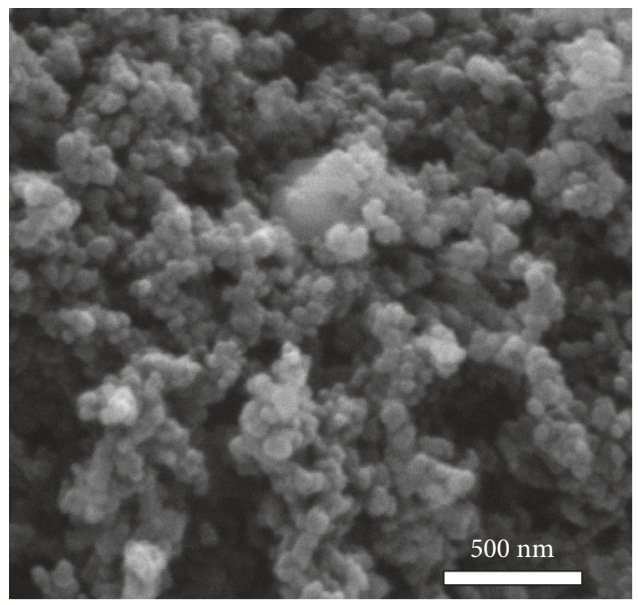

(a)

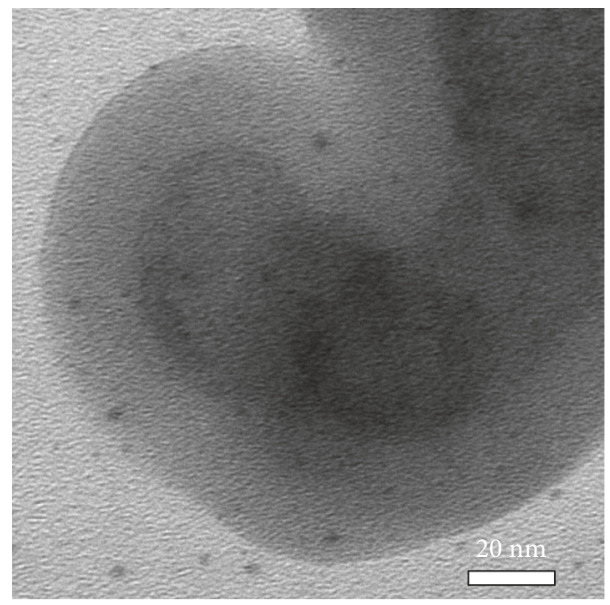

(b)

FIGURE 7: (a) SEM and (b) TEM images of the nanosilver-coated carbon black (AgCB) used as the additive for fabrication of $x$ AgCB-PBS composites ( $x=$ the percentages of AgCB filler with respect to the PBS content). 


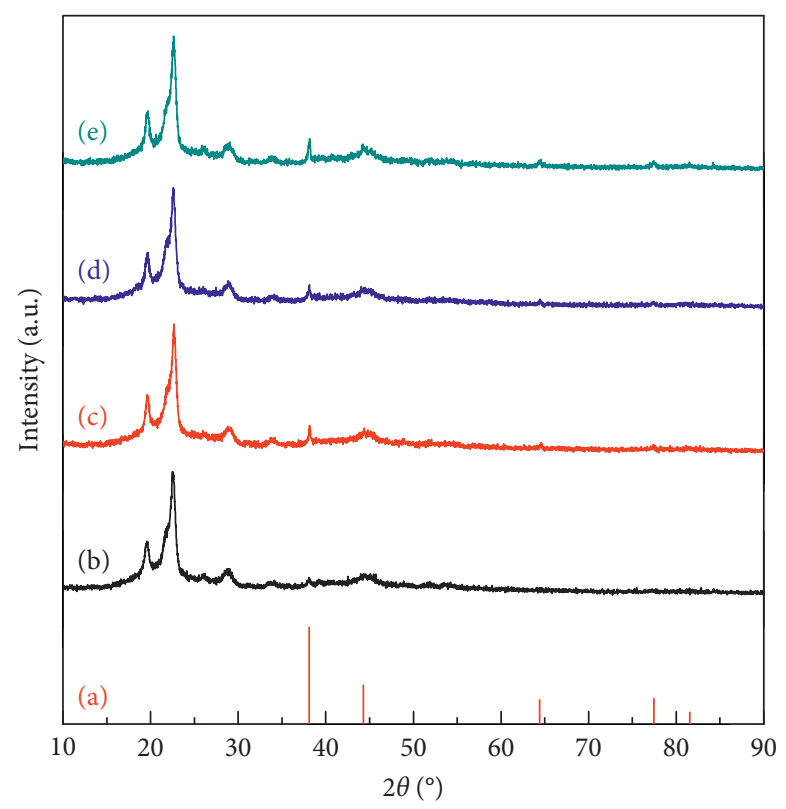

FIgURE 8: (a) Calculated XRD peaks of standard silver metal (JCPDS no. 04-0783) and the observed XRD patterns of (b) 3AgCB-PBS, (c) 5AgCB-PBS, (d) 10AgCB-PBS, and (e) 15AgCB-PBS composites.

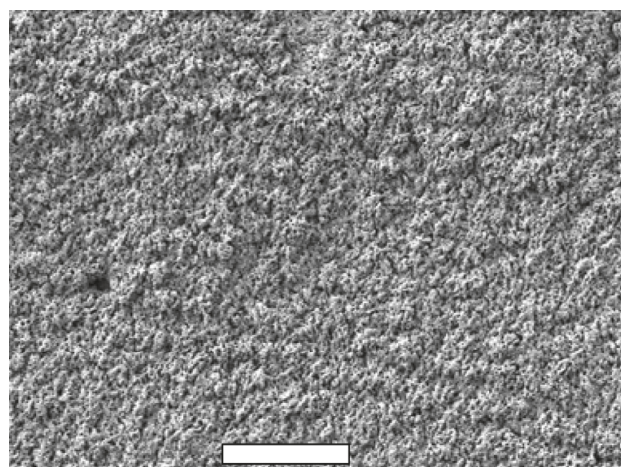

(a)

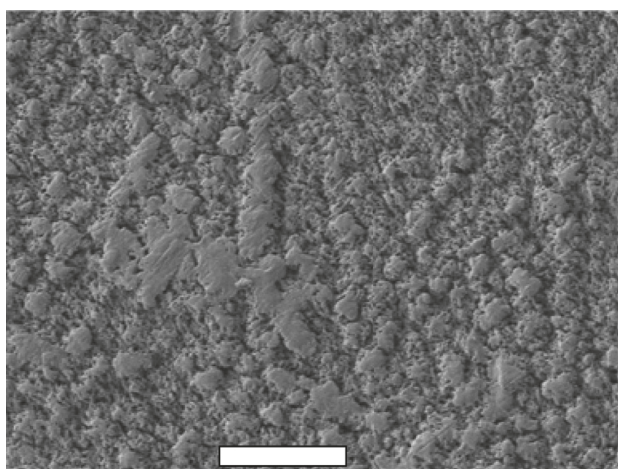

(c)

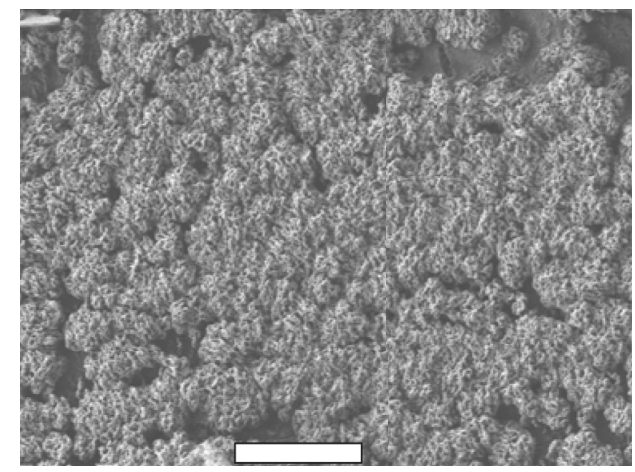

(b)

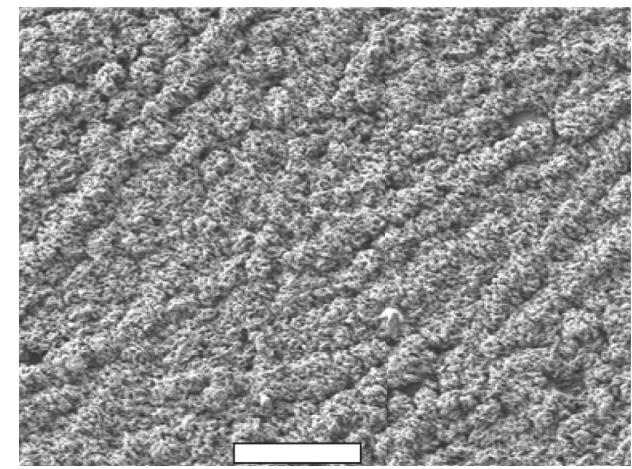

(d)

Figure 9: Continued. 


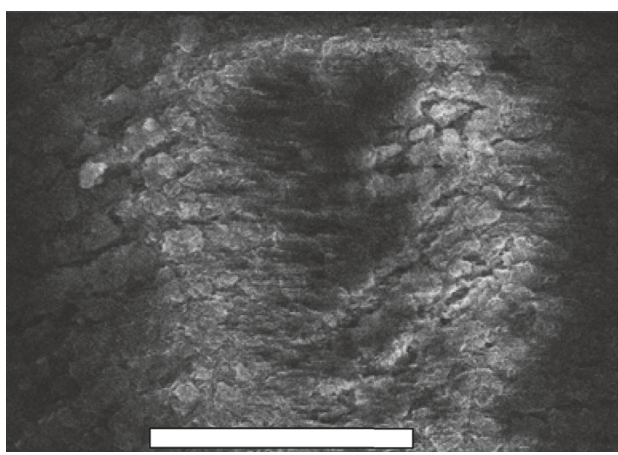

(e)

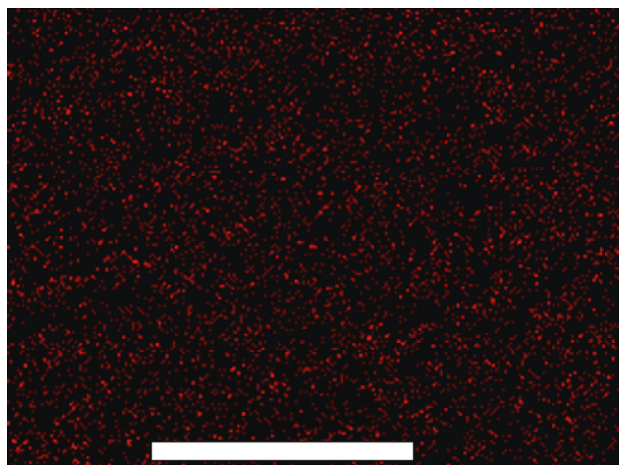

(g)

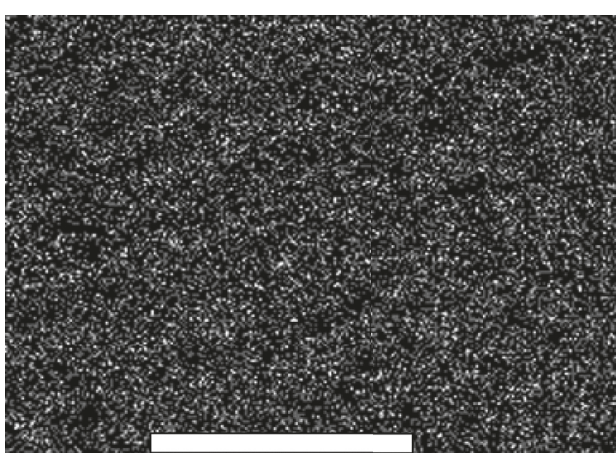

(f)

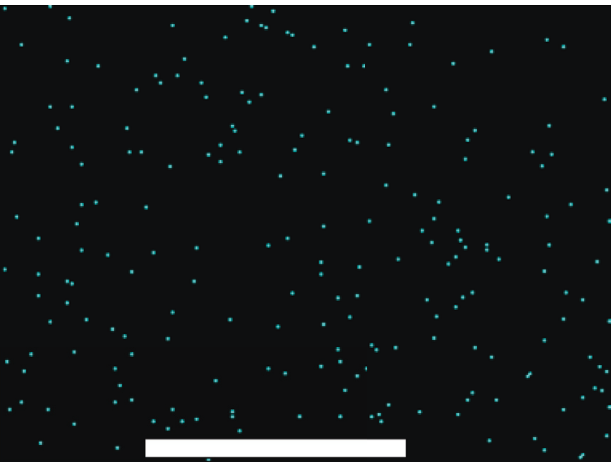

(h)

Figure 9: SEM images of (a) the pristine PBS in comparison with the (b) 3AgCB-PBS, (c) 5AgCB-PBS, (d) 10AgCB-PBS, and (e) 15AgCBPBS composites. The corresponding EDS elemental mappings of (f) C element, (g) O element, and (h) Ag element of the 15AgCB-PBS composite illustrate the well distribution of the $\mathrm{AgCB}$ additive within the PBS matrix. Note that the scale bar depicted in Figures 9(a) to 9(d) is $10 \mu \mathrm{m}$, while the one depicted in Figures 9(e) to 9(h) is $20 \mu \mathrm{m}$.

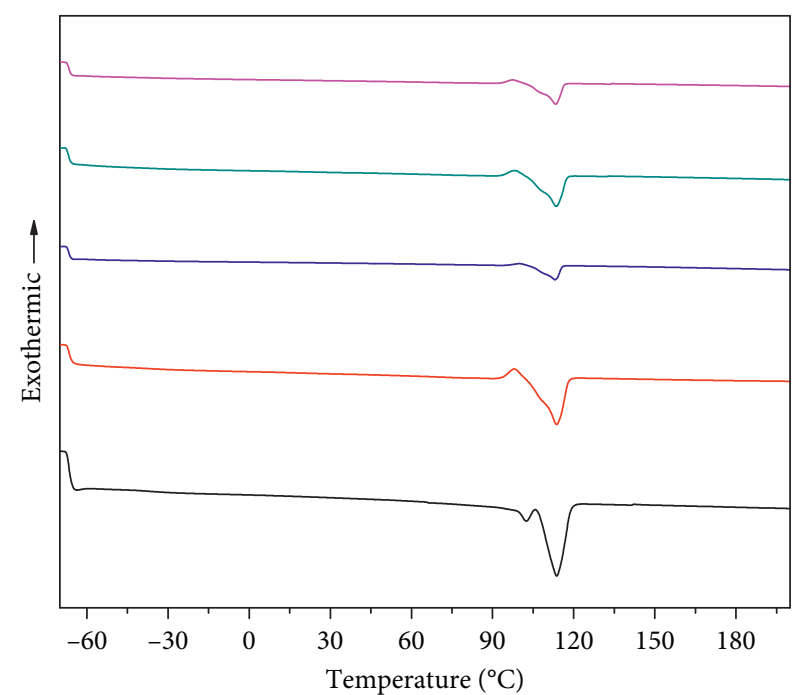

$(\mathrm{A})$
$-(\mathrm{B})$
$-(\mathrm{C})$

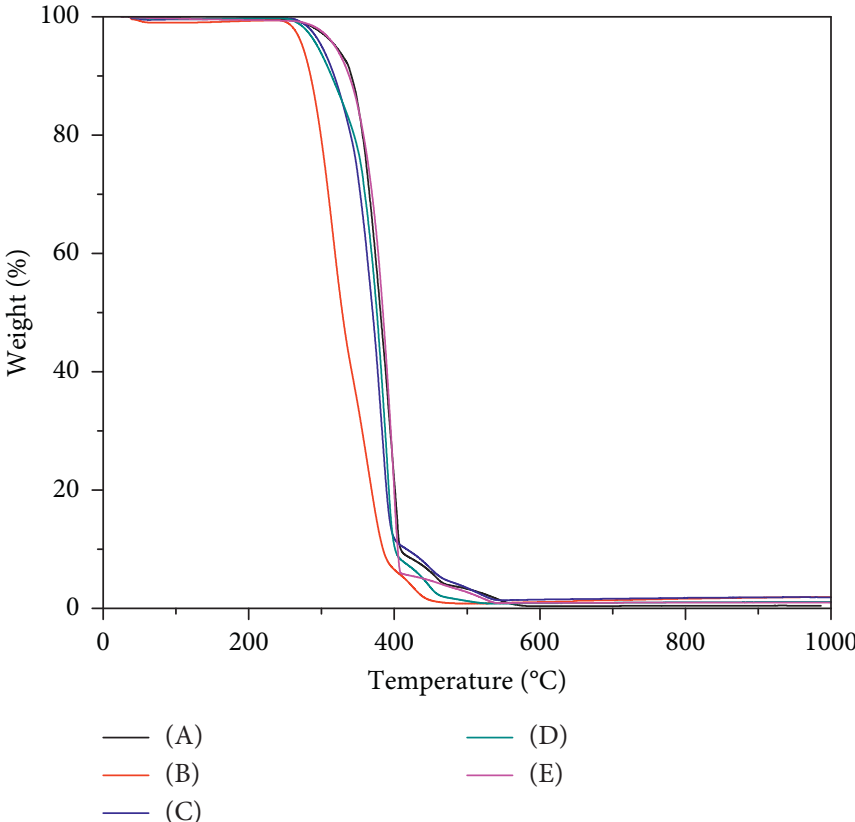

(b)

FIgURE 10: (a) DSC and (b) TGA thermograms of the pristine PBS and the AgCB-PBS composite materials. Note that the labels shown in the plots represent the materials as follows: (A) PBS, (B) 3AgCB-PBS, (C) 5AgCB-PBS, (D) 10AgCB-PBS, and (E) 15AgCB-PBS. 


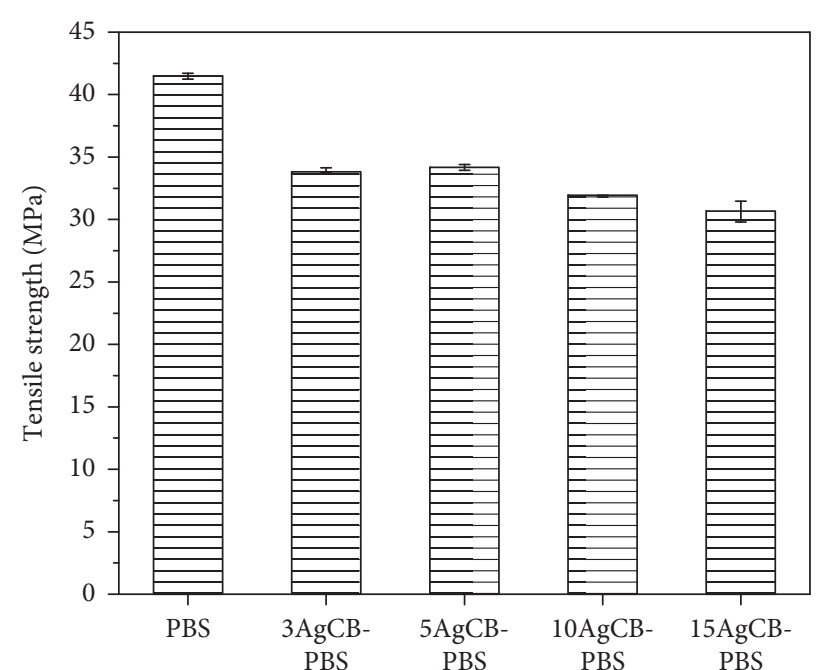

(a)

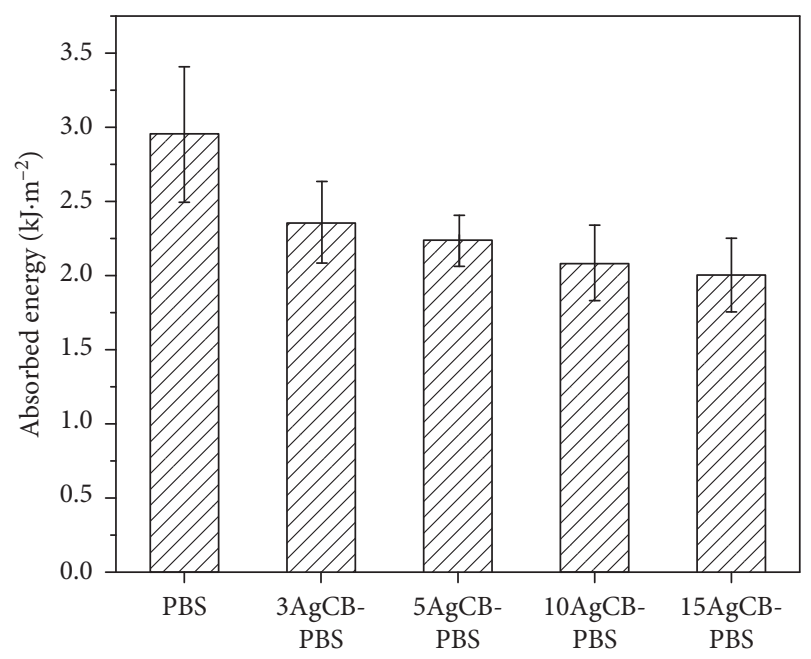

(c)

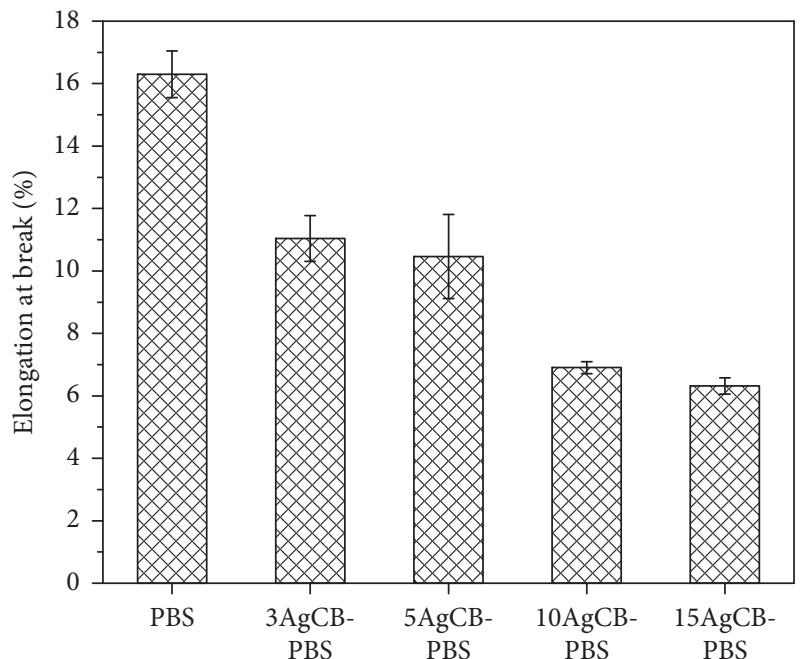

(b)

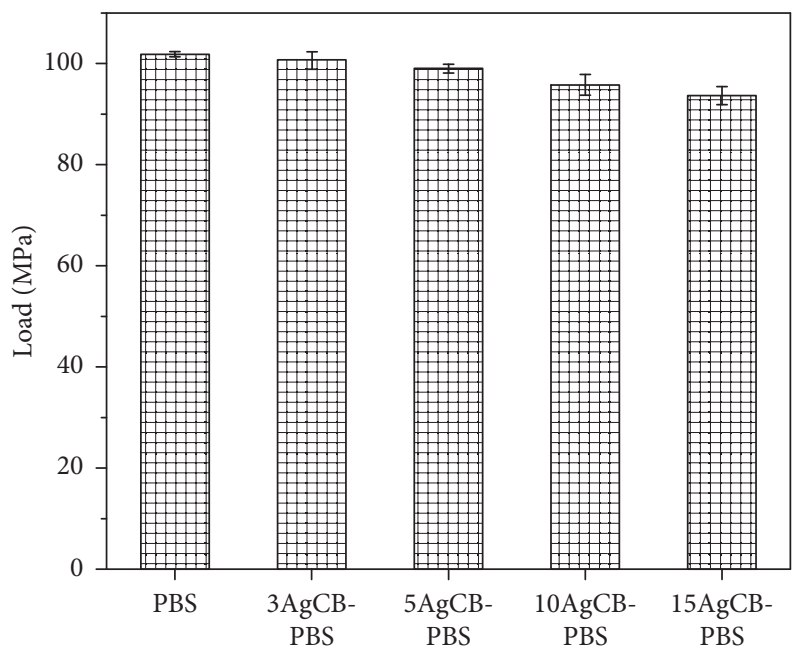

(d)

FIgURe 11: (a) Tensile strength, (b) elongation at break, (c) impact strength, and (d) bending strength of the pristine PBS as well as the $x$ AgCB-PBS composite materials.

composites are not straightforwardly related to the presence of Ag particles but rather the $\mathrm{CB}$ additive. In detail, tensile strengths for 3AgCB-PBS, 5AgCB-PBS, 10AgCB$\mathrm{PBS}$, and $15 \mathrm{AgCB}-\mathrm{PBS}$ were $36.83 \pm 0.65,33.29 \pm 0.53$, $35.98 \pm 0.13$, and $34.77 \pm 1.17 \mathrm{MPa}$, respectively (Figure 11(a)). For the test of elongation at break, the 3CB-PBS, 5CB-PBS, 10CB-PBS, and 15CB-PBS composites reveal the value of $13.04 \pm 0.15 \%, 8.28 \pm 0.58 \%, 12.97 \pm 0.44 \%$, and $8.12 \pm 0.77 \%$, respectively. Moreover, impact strengths of 3CB-PBS, 5CBPBS, 10CB-PBS, and 15CB-PBS are $2.36 \pm 0.60,2.08 \pm 0.57$, $2.35 \pm 0.20$, and $2.16 \pm 0.30 \mathrm{~kJ} / \mathrm{m}^{2}$. The bending strengths of $3 \mathrm{CB}-\mathrm{PBS}$, 5CB-PBS, 10CB-PBS, and 15CB-PBS gradually decrease from $101.69,92.39,82.95$, to $71.77 \mathrm{MPa}$, respectively.

To prove the enhanced characteristic features of the composites by means of the presence of $\mathrm{Ag}$ particles within the composites, the electrical conductivity of the AgCB-PBS composite materials was measured in comparison with the pristine PBS. The results clearly show an improvement of the electrical conductivity of the AgCB-PBS composites for approximately an order of magnitude. Specifically, the pristine PBS has a conductivity of $1.73 \times 10^{-7}(\Omega \mathrm{m})^{-1}$, whereas the $3 \mathrm{AgCB}-\mathrm{PBS}$, 5AgCB-PBS, 10AgCB-PBS, and 15AgCB-PBS reveals the electrical conductivity of $2.28 \times 10^{-6}, 3.62 \times 10^{-7}$, $9.40 \times 10^{-7}$, and $3.01 \times 10^{-6}(\Omega \mathrm{m})^{-1}$, respectively. Note that, the electrical conductivities of AgCB-PBS composite materials observed herein are even higher for about an order of magnitude than those of AgCB-PLA composite materials prepared by using a similar procedure reported by our group previously [39]. This result highlights the possibility of using these AgCB-PBS composite materials for antielectrostatic applications, e.g., antifouling plastics.

Not only an enhancement of electrical conductivity, the antimicrobial activities of the AgCB-PBS composites were also studied by the agar disk diffusion method using different microorganisms, namely, S. aureus (ATCC 25923), B. subtilis (ATCC 6633), M. luteus (ATCC 9341), E. coli (ATCC 25922), P. aeruginosa (ATCC 2785), and C. albicans (ATCC 10231) (Figure 12 and Table 1). The bacteria being studied in 


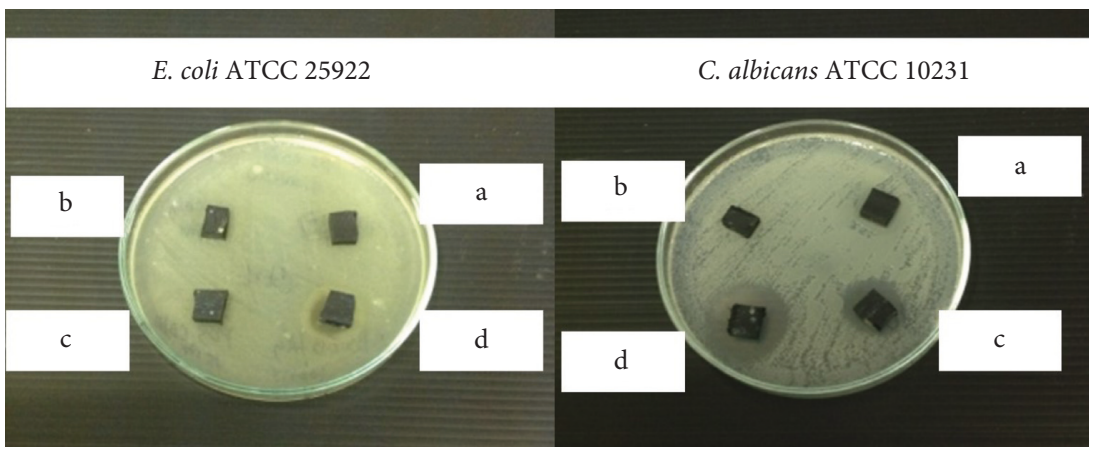

Figure 12: Positive tests for antimicrobial properties on E. coli and C. albicans using the agar disk diffusion method of (a) 3AgCB-PBS, (b) 5AgCB-PBS, (c) 10AgCB-PBS, and (d) 15AgCB-PBS composite materials.

TABLE 1: Antimicrobial properties of AgCB-PBS composite materials.

\begin{tabular}{|c|c|c|c|c|c|c|}
\hline \multirow[b]{2}{*}{$\begin{array}{l}\text { Nanosilver-coated } \\
\text { material }\end{array}$} & \multicolumn{6}{|c|}{ Microbial strains (clear zone) } \\
\hline & $\begin{array}{c}\text { E. coli ATCC } \\
25922 \\
\end{array}$ & $\begin{array}{c}\text { S. aureus ATCC } \\
25923\end{array}$ & $\begin{array}{c}\text { P. aeruginosa } \\
\text { ATCC } 2785\end{array}$ & $\begin{array}{c}\text { M. luteus ATCC } \\
9341\end{array}$ & $\begin{array}{c}\text { B. subtilis ATCC } \\
6633 \\
\end{array}$ & $\begin{array}{c}\text { C. albicans ATCC } \\
10231 \\
\end{array}$ \\
\hline $3 \mathrm{AgCB}-\mathrm{PBS}$ & - & - & - & - & - & - \\
\hline 5AgCB-PBS & - & - & - & - & - & - \\
\hline 10AgCB-PBS & - & - & - & - & - & + \\
\hline 15AgCB-PBS & + & - & - & - & - & + \\
\hline
\end{tabular}

this work have different types of cell walls. They can be classified into two groups, i.e., Gram-negative bacteria and Gram-positive bacteria. E. coli (ATCC 25922) and P. aeruginosa (ATCC 2785) are Gram-negative bacteria while $S$. aureus (ATCC 25923), M. luteus (ATCC 9341), and $B$. subtilis (ATCC 6633) are Gram-positive bacteria. The antimicrobial study (Figure 12 and Table 1) shows that the silver nanoparticles within the AgCB-PBS composites reveal a stronger activity against the Gram-negative bacteria than the Gram-positive bacteria, which agrees well with the previous literature [41, 42]. The difference in antimicrobial activity might be due to their different cell wall structures $[43,44]$. The Gram-positive bacteria consist of the thicker peptidoglycan (20-80 nm) than Gram-negative bacteria (7$8 \mathrm{~nm}$ ) [43]. Therefore, the thicker peptidoglycan sheet might prevent the penetration of silver nanoparticles from getting into the bacterial cells to damage them. The other type of microorganisms, namely, C. albicans, pathogenic yeast, was also investigated. It is observed that the fabricated AgCBPBS composite materials illustrate greater inhibition zones than both the Gram-positive and Gram-negative bacteria. This result is similar to the study reported by Parthiban et al. [45]. Again the activity is mainly related to the cell wall structure of the microorganisms. Overall, our research work discloses the development of antimicrobial biocomposites. Among all the samples, 15AgCB-PBS shows the most effective inhibition zone against $E$. coli (ATCC 25922) and $C$. albicans (ATCC 10231), highlighting the role of Ag particles within the AgCB-PBS composites.

An additional phase analysis of the 1-year-aged CB-PBS and AgCB-PBS composite materials was performed using the synchrotron-based grazing incidence XRD (GIXRD). The GIXRD patterns (Figure 13) reveal that there is only the crystalline PBS polymer matrix phase presented at the surface part of the materials in all the cases. This observation suggests that the AgCB-PBS composites gradually degraded due to the leaking of crystalline Ag nanoparticles as well as the reaction with the microbes especially at the surface of materials when the materials are placed in the ambient atmosphere for a longer time. This emphasizes the fact that even though the AgCB-PBS composites exhibit the antimicrobial properties, they are still biodegradable. Hence, these AgCB-PBS composites could be one of the promising candidates for environmentally friendly plastics for the future.

\section{Conclusion}

In this work, the pre-formed additive so-called nanosilvercoated carbon black (AgCB), which was prepared by the benzoxazine oxidation method to distribute silver nanoparticles onto the surface of carbon black, is used to blend with the PBS polymer matrix in order to enhance its characteristic features. Phase identification using XRD of the as-fabricated CB-PBS and AgCB-PBS composites fabricated by the injection molding mainly shows the XRD peaks according to the crystalline phase of the PBS matrix. The XRD peaks of metallic silver particles are additionally observed in the as-fabricated materials, indicating the successful preparation of the AgCB-PBS composite materials. Addition of the $\mathrm{CB}$ and AgCB fillers affects the glass transition temperature, the endothermic melting peak, and the thermal decomposition temperature of the PBS matrix. Mechanical properties in terms of tensile strength, elongation at break, impact strength, and bending strength are slightly decreased in the composites in comparison with the pristine PBS materials. However, they are still within the acceptable regions. As a highlight of this work, AgCB-PBS 


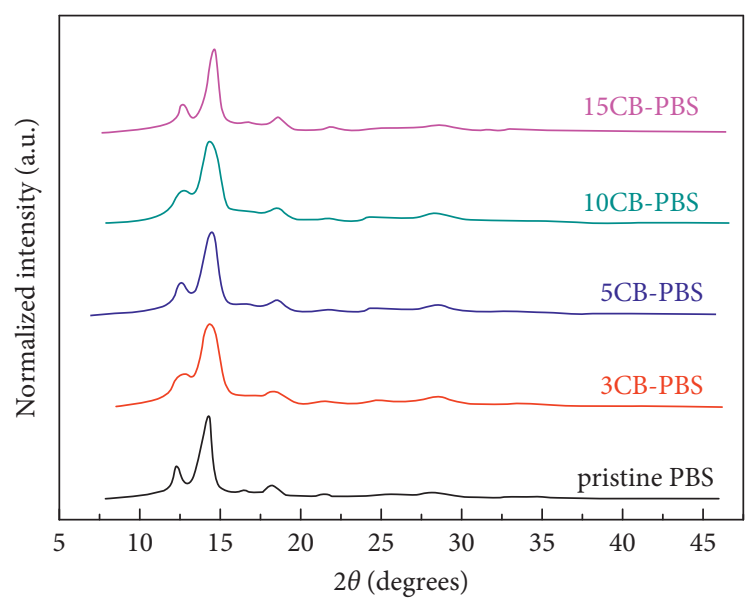

(a)

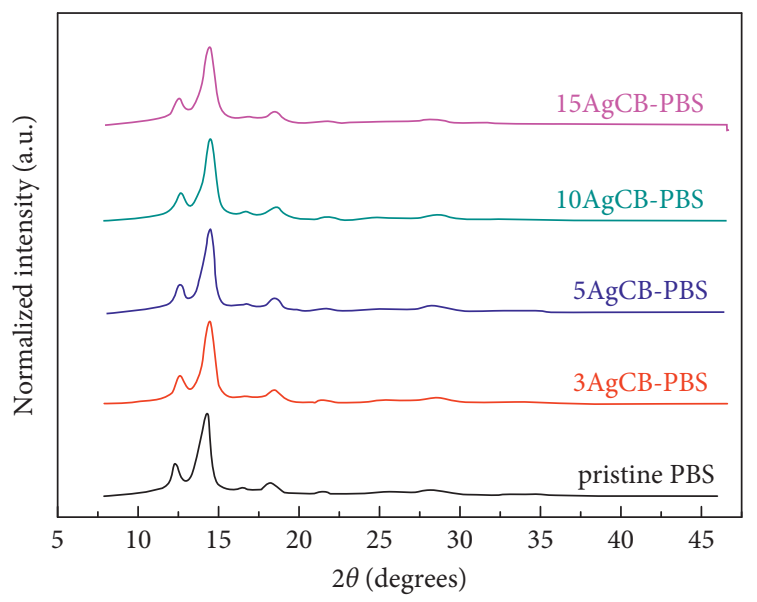

(b)

FIgURE 13: One-dimensional integration XRD patterns of the 1year-aged (a) xCB-PBS composites and (b) xAgCB-PBS composites in comparison with the pristine PBS material obtained from the two-dimensional grazing incidence X-ray diffraction (2d-GIXRD) patterns using synchrotron monochromatic X-ray of energy $12 \mathrm{keV}$ (wavelength of $1.0332 \AA$ ) and grazing incidence angle of $0.5^{\circ}$.

composite materials, especially the $15 \mathrm{AgCB}-\mathrm{PBS}$, reveal an enhancement of the electrical conductivity for approximately an order of magnitude as well as exhibit the antimicrobial activities for inhibition against $S$. aureus and $C$. albicans using the agar disk diffusion test. The fabricated AgCB-PBS composite materials are expected to be one of the suitable candidate materials for producing smart keyboards as they have good antimicrobial and electrical properties, which could reduce the requirements for the cleaning process.

\section{Data Availability}

The data used to support the findings of this study are available upon request through Dr. Worawat Wattanathana via e-mail (fengwwwa@ku.ac.th), or through Assoc. Prof. Dr. Apirat Laobuthee via e-mail (fengapl@ku.ac.th).

\section{Conflicts of Interest}

The authors declare there are no conflicts of interest regarding the publication of this paper.

\section{Acknowledgments}

The authors would like to acknowledge the financial support from the National Research Council of Thailand (NRCT) and Kasetsart University Research and Development Institute (KURDI). Appreciation is also expressed to the Department of Materials Engineering, Faculty of Engineering, Kasetsart University, and Department of Chemistry, Faculty of Science, Kasetsart University, for the support of research facilities. Beamline 1.1W (Multiple X-ray Techniques, MXT) of the Synchrotron Light Research Institute, Thailand, is acknowledged for the GIXRD beamtime and the facilities during GIXRD measurements.

\section{References}

[1] X. Luo, J. Li, and X. Lin, "Effect of gelatinization and additives on morphology and thermal behavior of corn starch/PVA blend films," Carbohydrate Polymers, vol. 90, no. 4, pp. 1595-1600, 2012.

[2] J. Prachayawarakorn, L. Hommanee, D. Phosee, and P. Chairapaksatien, "Property improvement of thermoplastic mung bean starch using cotton fiber and low-density polyethylene," Starch-Stärke, vol. 62, no. 8, pp. 435-443, 2010.

[3] F. Z. Arrakhiz, K. Benmoussa, R. Bouhfid, and A. Qaiss, "Pine cone fiber/clay hybrid composite: mechanical and thermal properties," Materials \& Design, vol. 50, pp. 376-381, 2013.

[4] N. Sutivisedsak, H. N. Cheng, M. K. Dowd, G. W. Selling, and A. Biswas, "Evaluation of cotton byproducts as fillers for poly(lactic acid) and low density polyethylene," Industrial Crops and Products, vol. 36, no. 1, pp. 127-134, 2012.

[5] E. R. Coats, F. J. Loge, M. P. Wolcott, K. Englund, and A. G. McDonald, "Production of natural fiber reinforced thermoplastic composites through the use of polyhydroxybutyraterich biomass," Bioresource Technology, vol. 99, no. 7, pp. 26802686, 2008.

[6] M. Delgado-Aguilar, H. Oliver-Ortega, J. Alberto Méndez, J. Camps, F. X. Espinach, and P. Mutjé, "The role of lignin on the mechanical performance of polylactic acid and jute composites," International Journal of Biological Macromolecules, vol. 116, pp. 299-304, 2018.

[7] J. Ye, S. Wang, W. Lan, W. Qin, and Y. Liu, "Preparation and properties of polylactic acid-teapolyphenol-chitosan composite membranes," International Journal of Biological Macromolecules, vol. 117, pp. 632-639, 2018.

[8] H. E. Salama, M. S. A. Aziz, and G. R. Saad, "Thermal properties, crystallization and antimicrobial activity of chitosan biguanidine grafted poly(3-hydroxybutyrate) containing silver nanoparticles," International Journal of Biological Macromolecules, vol. 111, pp. 19-27, 2018.

[9] D. Garcia-Garcia, J. Lopez-Martinez, R. Balart, E. Strömberg, and R. Moriana, "Reinforcing capability of cellulose nanocrystals obtained from pine cones in a biodegradable poly(3hydroxybutyrate)/poly( $\varepsilon$-caprolactone) (PHB/PCL) thermoplastic blend," European Polymer Journal, vol. 104, pp. 10-18, 2018. 
[10] K. Shi, Y. Liu, X. Hu, T. Su, P. Li, and Z. Wang, "Preparation, characterization, and biodegradation of poly(butylene succinate)/cellulose triacetate blends," International Journal of Biological Macromolecules, vol. 114, pp. 373-380, 2018.

[11] Z. Huang, L. Qian, Q. Yin, N. Yu, T. Liu, and D. Tian, "Biodegradability studies of poly(butylene succinate) composites filled with sugarcane rind fiber," Polymer Testing, vol. 66, pp. 319-326, 2018.

[12] P. Liminana, D. Garcia-Sanoguera, L. Quiles-Carrillo, R. Balart, and N. Montanes, "Development and characterization of environmentally friendly composites from poly(butylene succinate) (PBS) and almond shell flour with different compatibilizers," Composites Part B: Engineering, vol. 144, pp. 153-162, 2018.

[13] W.-G. Liu, X.-C. Zhang, H.-Y. Li, and Z. Liu, "Effect of surface modification with 3-aminopropyltriethyloxy silane on mechanical and crystallization performances of $\mathrm{ZnO} /$ poly(butylenesuccinate) composites," Composites Part B: Engineering, vol. 43, no. 5, pp. 2209-2216, 2012.

[14] N. Petchwattana, S. Covavisaruch, S. Wibooranawong, and P. Naknaen, "Antimicrobial food packaging prepared from poly(butylene succinate) and zinc oxide," Measurement, vol. 93, pp. 442-448, 2016.

[15] J. Li, X. Luo, and X. Lin, "Preparation and characterization of hollow glass microsphere reinforced poly(butylene succinate) composites," Materials \& Design, vol. 46, pp. 902-909, 2013.

[16] W. Guo, Y. Zhang, and W. Zhang, "Mechanical properties and crystallization behavior of hydroxyapatite/poly(butylenes succinate) composites," Journal of Biomedical Materials Research Part A, vol. 101, no. 9, pp. 2500-2506, 2013.

[17] P. Č́hal, O. Vopička, M. Lanč et al., "Poly(butylene succinate)-cellulose triacetate blends: permeation, pervaporation, sorption and physical structure," Polymer Testing, vol. 65, pp. 468-479, 2018.

[18] X. Zhang, J. Shi, H. Ye, Y. Dong, and Q. Zhou, "Combined effect of cellulose nanocrystals and poly(butylene succinate) on poly(lactic acid) crystallization: the role of interfacial affinity," Carbohydrate Polymers, vol. 179, pp. 79-85, 2018.

[19] E. Frollini, N. Bartolucci, L. Sisti, and A. Celli, "Poly(butylene succinate) reinforced with different lignocellulosic fibers," Industrial Crops and Products, vol. 45, pp. 160-169, 2013.

[20] O. Faruk, A. K. Bledzki, H.-P. Fink, and M. Sain, "Biocomposites reinforced with natural fibers: 2000-2010," Progress in Polymer Science, vol. 37, no. 11, pp. 1552-1596, 2012.

[21] T. H. Nam, S. Ogihara, H. Nakatani, S. Kobayashi, J. I. Song, and J. I. Song, "Mechanical and thermal properties and water absorption of jute fiber reinforced poly(butylene succinate) biodegradable composites," Advanced Composite Materials, vol. 21, no. 3, pp. 241-258, 2012.

[22] T. H. Nam, S. Ogihara, N. H. Tung, and S. Kobayashi, "Effect of alkali treatment on interfacial and mechanical properties of coir fiber reinforced poly(butylene succinate) biodegradable composites," Composites Part B: Engineering, vol. 42, no. 6, pp. 1648-1656, 2011.

[23] S.-M. Lai, Y.-H. Kao, Y.-K. Liu, and F.-C. Chiu, "Preparation and properties of luffa fiber- and kenaf fiber-filled poly(butylene succinate-co-lactate)/starchblend-based biocomposites," Polymer Testing, vol. 50, pp. 191-199, 2016.

[24] L. Maubane, S. S. Ray, and K. Jalama, "The effect of starch amylose content on the morphology and properties of meltprocessedbutyl-etherifiedstarch/poly[(butylene succinate)co-adipate] blends," Carbohydrate Polymers, vol. 155, pp. 89-100, 2017.
[25] F. Chen and J. Zhang, "In-situ poly(butylene adipate-coterephthalate)/soy protein concentrate composites: effects of compatibilization and composition on properties," Polymer, vol. 51, no. 8, pp. 1812-1819, 2010.

[26] S. Bonham, M. Misra, and A. K. Mohanty, "Effect of corotation and counter-rotation extrusion processing on the thermal and mechanical properties, and morphology of plasticized soy protein isolate and poly(butylene succinate) blends," Macromolecular Materials and Engineering, vol. 296, no. 9, pp. 788-801, 2011.

[27] M. M. Reddy, A. K. Mohanty, and M. Misra, "Biodegradable blends from plasticized soy meal, polycaprolactone, and poly(butylene succinate)," Macromolecular Materials and Engineering, vol. 297, no. 5, pp. 455-463, 2012.

[28] Y. Pan, X. Liu, J. Kaschta, X. Hao, C. Liu, and D. W. Schubert, "Viscoelastic and electrical behavior of poly(methyl methacrylate)/carbon black composites prior to and after annealing," Polymer, vol. 113, pp. 34-38, 2017.

[29] G. X. Mao and A. F. Zhu, "Enhanced electrically conductive polypropylene/nano carbon black composite," PolymerPlastics Technology and Engineering, vol. 51, no. 10, pp. 1073-1076, 2012.

[30] L.-F. Ma, R.-Y. Bao, S.-L. Huang et al., "Electrical properties and morphology of carbon black filled PP/EPDM blends: effect of selective distribution of fillers induced by dynamic vulcanization," Journal of Materials Science, vol. 48, no. 14, pp. 4942-4951, 2013.

[31] Y.-H. Zhao, Y.-F. Zhang, Z.-K. Wu, and S.-L. Bai, "Synergic enhancement of thermal properties of polymer composites by graphene foam and carbon black," Composites Part B: Engineering, vol. 84, pp. 52-58, 2016.

[32] X. Chen and H. J. Schluesener, "Nanosilver: a nanoproduct in medical application," Toxicology Letters, vol. 176, no. 1, pp. 1-12, 2008.

[33] J.-W. Rhim, H.-M. Park, and C.-S. Ha, "Bio-nanocomposites for food packaging applications," Progress in Polymer Science, vol. 38, no. 10-11, pp. 1629-1652, 2013.

[34] T. V. Duncan, "Applications of nanotechnology in food packaging and food safety: barrier materials, antimicrobials and sensors," Journal of Colloid and Interface Science, vol. 363, no. 1, pp. 1-24, 2011.

[35] A. Kaewvilai, W. Wattanathana, S. Jongrungruangchok, C. Veranitisagul, N. Koonsaeng, and A. Laobuthee, "3,4dihydro-1,3-2 H -benzoxazines: novel reducing agents through one electron donation mechanism and their application as the formation of nano-metallic silver coating," Materials Chemistry and Physics, vol. 167, pp. 9-13, 2015.

[36] L. G. Reimer, Antibiotics in Laboratory Medicine, Williams \& Wilkins, Baltimore, MD, USA, 2nd edition, 1986.

[37] Y.-D. Li, H. Li, A.-K. Du, M. Wang, and J.-B. Zeng, "Morphology and isothermal crystallization of graphene oxide reinforced biodegradable poly(butylene succinate)," Polymer Testing, vol. 59, pp. 1-9, 2017.

[38] X. Luo, J. Li, J. Feng, T. Yang, and X. Lin, "Mechanical and thermal performance of distillers grains filled poly(butylene succinate) composites," Materials \& Design, vol. 57, pp. 195-200, 2014.

[39] N. Nootsuwan, W. Wattanathana, S. Jongrungruangchok, C. Veranitisagul, N. Koonsaeng, and A. Laobuthee, "Development of novel hybrid materials from polylactic acid and nano-silver coated carbon black with distinct antimicrobial and electrical properties," Journal of Polymer Research, vol. 25, no. 4, 2018. 
[40] N. Nootsuwan, K. Sukthavorn, W. Wattanathana et al., "Development of antimicrobial hybrid materials from polylactic acid and nano-silver coated chitosan," Oriental Journal of Chemistry, vol. 34, no. 2, pp. 683-692, 2018.

[41] S. Shankar, J.-W. Rhim, and K. Won, "Preparation of poly(lactide)/lignin/silver nanoparticles composite films with UV light barrier and antibacterial properties," International Journal of Biological Macromolecules, vol. 107, pp. 1724-1731, 2018.

[42] S. Shankar, L.-F. Wang, and J.-W. Rhim, "Preparations and characterization of alginate/silver composite films: effect of types of silver particles," Carbohydrate Polymers, vol. 146, pp. 208-216, 2016.

[43] S. Priyadarshini, V. Gopinath, N. Meera Priyadharsshini, D. MubarakAli, and P. Velusamy, "Synthesis of anisotropic silver nanoparticles using novel strain, Bacillus flexus and its biomedical application," Colloids and Surfaces B: Biointerfaces, vol. 102, pp. 232-237, 2013.

[44] S. Shankar, L. Jaiswal, R. S. L. Aparna, and R. G. S. V. Prasad, "Synthesis, characterization, in vitro biocompatibility, and antimicrobial activity of gold, silver and gold silver alloy nanoparticles prepared from Lansium domesticum fruit peel extract," Materials Letters, vol. 137, pp. 75-78, 2014.

[45] E. Parthiban, N. Manivannan, R. Ramanibai, and N. Mathivanan, "Green synthesis of silver-nanoparticles from Annona reticulata leaves aqueous extract and its mosquito larvicidal and anti-microbial activity on human pathogens," Biotechnology Reports, vol. 21, article e00297, 2019. 

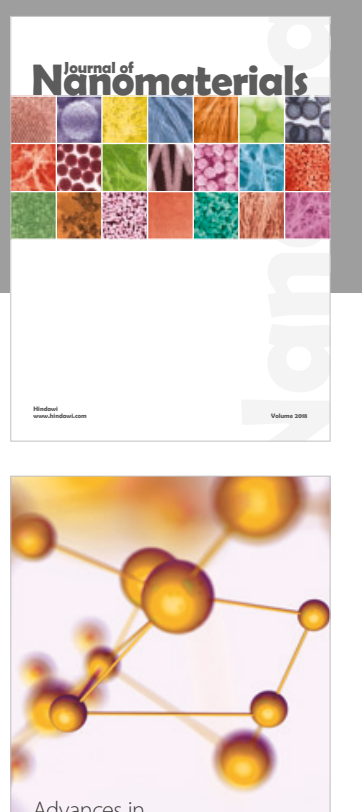

Physical Chemistry
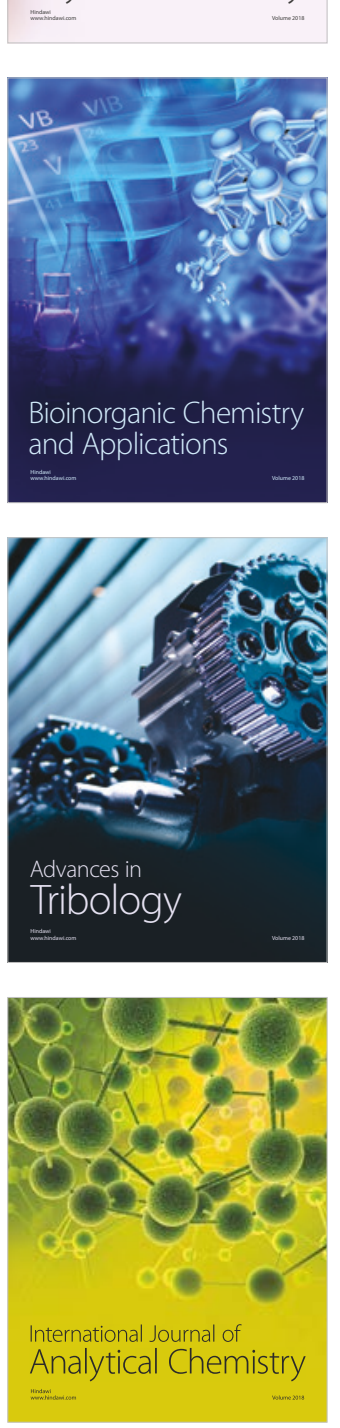

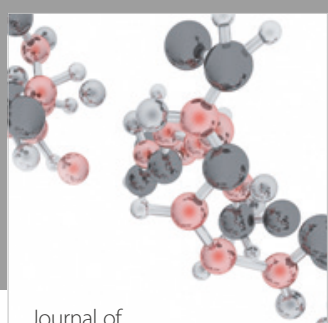

Analytical Methods

in Chemistry

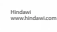

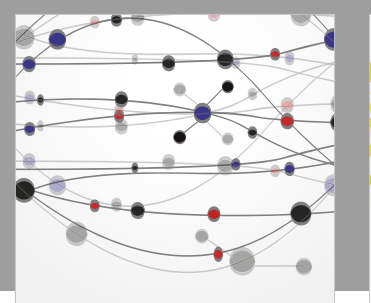

The Scientific World Journal

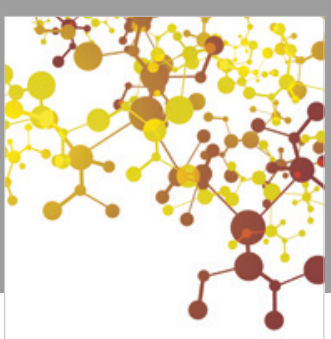

Journal of

Applied Chemistry
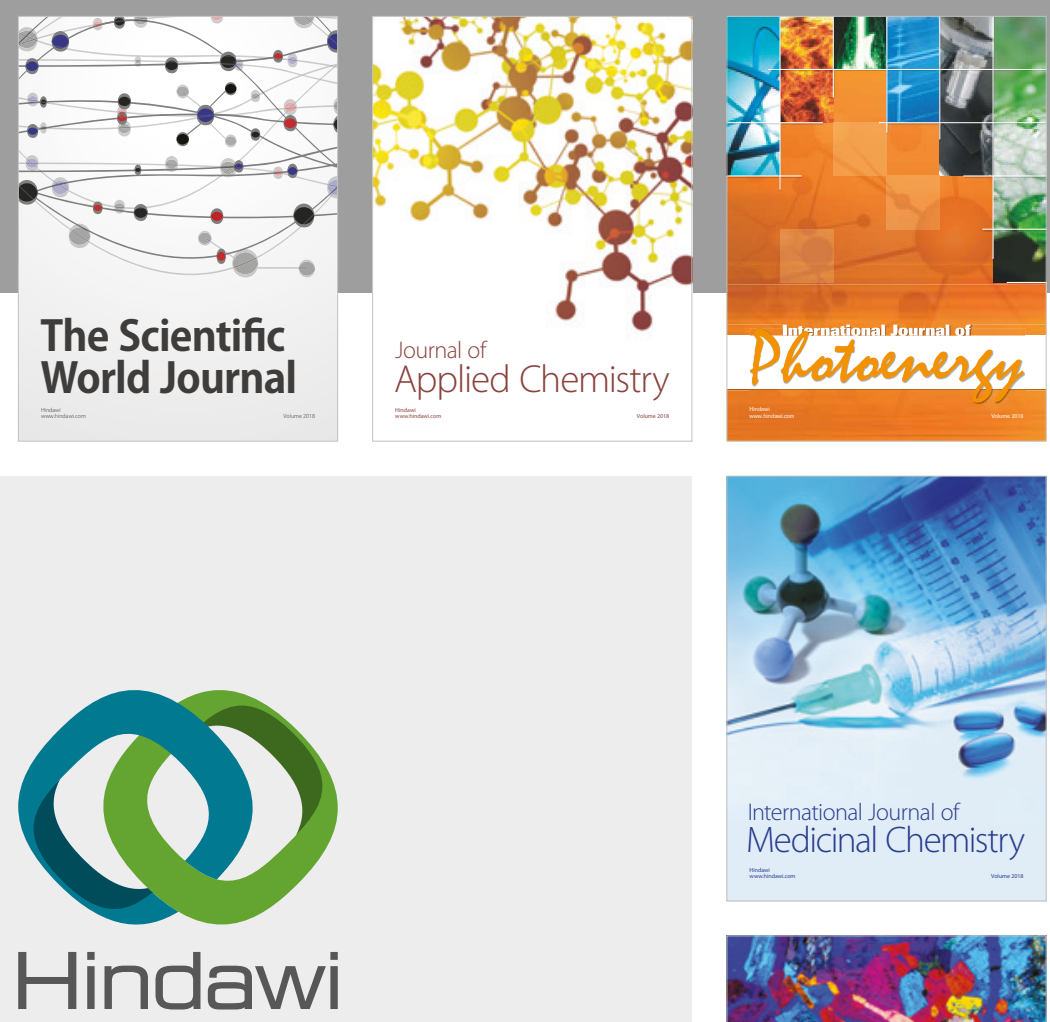

Submit your manuscripts at

www.hindawi.com
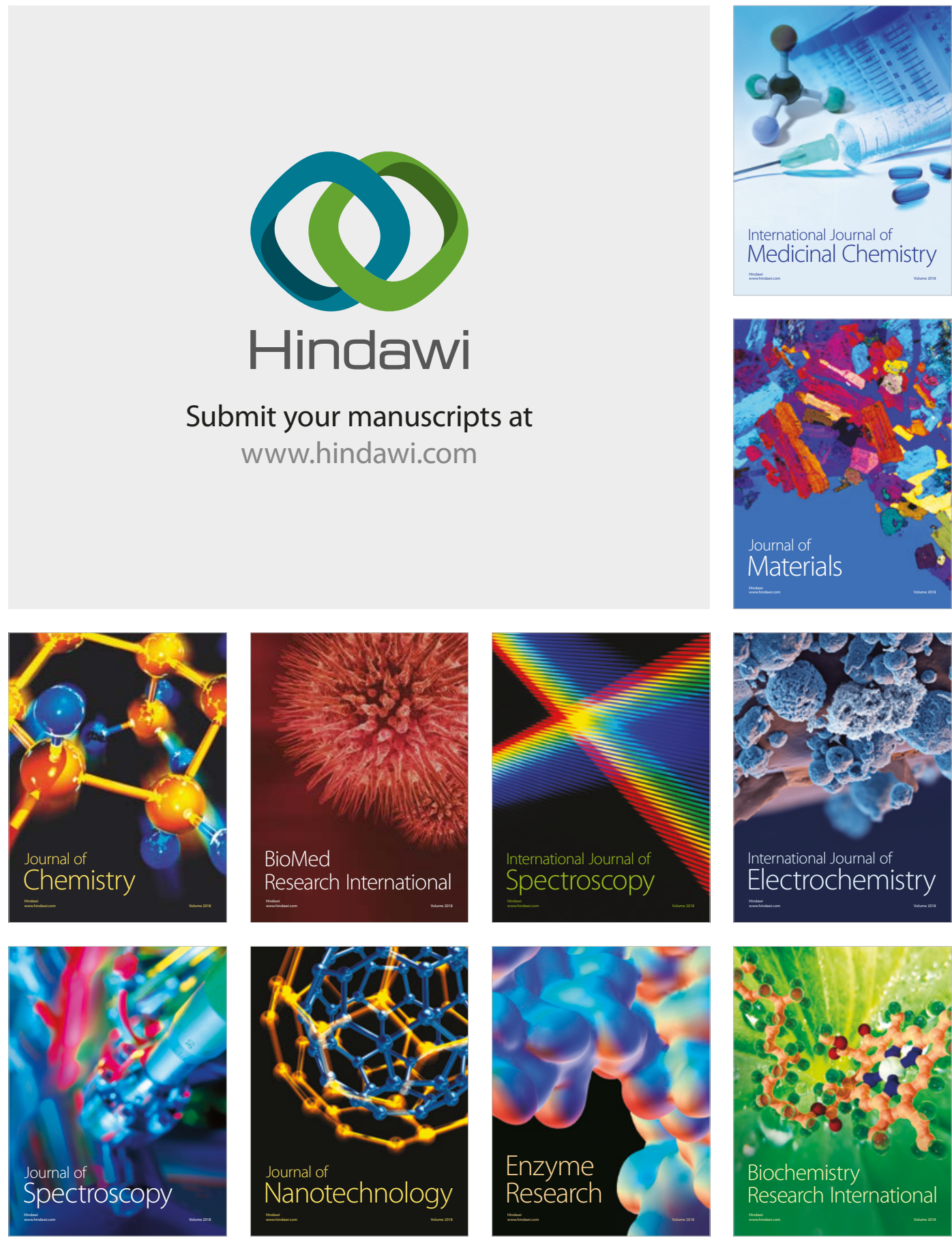
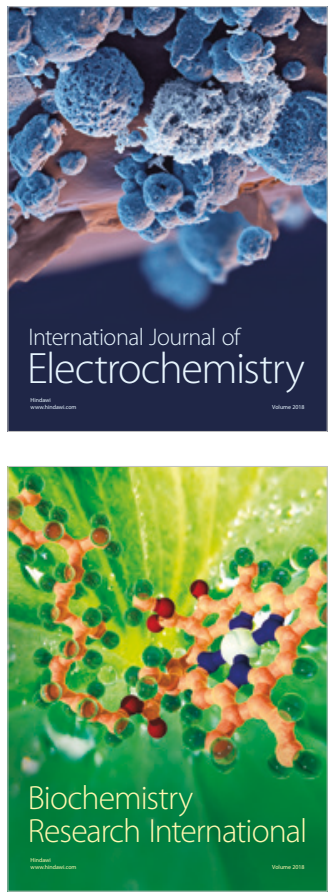